\title{
Nanoparticle-Based Paramagnetic Contrast Agents for Magnetic Resonance Imaging
}

\author{
Juan Pellico $\mathbb{D}$, Connor M. Ellis $\mathbb{D}$, and Jason J. Davis $\mathbb{D}$ \\ Department of Chemistry, University of Oxford, South Parks Road, Oxford OX1 3QZ, UK \\ Correspondence should be addressed to Jason J. Davis; jason.davis@chem.ox.ac.uk
}

Received 12 February 2019; Accepted 4 April 2019; Published 5 May 2019

Guest Editor: Paulo H. Rosado-de-Castro

Copyright (c) 2019 Juan Pellico et al. This is an open access article distributed under the Creative Commons Attribution License, which permits unrestricted use, distribution, and reproduction in any medium, provided the original work is properly cited.

\begin{abstract}
Magnetic resonance imaging (MRI) is a noninvasive medical imaging modality that is routinely used in clinics, providing anatomical information with micron resolution, soft tissue contrast, and deep penetration. Exogenous contrast agents increase image contrast by shortening longitudinal $\left(T_{1}\right)$ and transversal $\left(T_{2}\right)$ relaxation times. Most of the $T_{1}$ agents used in clinical MRI are based on paramagnetic lanthanide complexes (largely Gd-based). In moving to translatable formats of reduced toxicity, greater chemical stability, longer circulation times, higher contrast, more controlled functionalisation and additional imaging modalities, considerable effort has been applied to the development of nanoparticles bearing paramagnetic ions. This review summarises the most relevant examples in the synthesis and biomedical applications of paramagnetic nanoparticles as contrast agents for MRI and multimodal imaging. It includes the most recent developments in the field of production of agents with high relaxivities, which are key for effective contrast enhancement, exemplified through clinically relevant examples.
\end{abstract}

\section{Introduction}

Noninvasive imaging techniques support disease diagnosis and pathological characterisation with ease in a comparatively safe manner $[1,2]$. These techniques include nuclear imaging modalities such as positron emission tomography (PET), single photon emission computed tomography (SPECT), computed tomography (CT), optical imaging (OI), ultrasound (US), and magnetic resonance imaging (MRI). All these present individual distinct advantages, as well as limitations which need to be considered within the aims of the specific study. MRI is routinely utilised because of its associated intrinsic high spatial resolution, deep tissue penetration, and three-dimensional anatomical information [3]. It is, thus, widely employed in clinics for the diagnosis and prognosis of a broad range of disease states. Despite this, MRI suffers from inherently low sensitivity; hence, exogenous contrast agents are applied to overcome this obstacle by shortening the relaxation times of bulk water [4]. Contrast agents not only enhance image contrast but also support multimodal imaging. They can be classified into two different groups depending on the operational mode. $T_{1}$, also called positive contrast agents, shortens longitudinal relaxation times and brightens the accumulation area [5]. $T_{2}$, or negative contrast agents, conversely shortens transversal relaxation times and darkens the immediate and surrounding area. From metal complexes to nanoparticles, different formulations have been employed as contrast agents for MRI with most of these based on the use of highly paramagnetic ions such as $\mathrm{Gd}^{3+}, \mathrm{Mn}^{2+}$, and $\mathrm{Fe}^{3+}$ [6]. They are usually utilised as coordination complexes with acyclic or cyclic chelate agents to reduce associated toxicity of the free metal ion. Although these molecular agents have been extensively used, paramagnetic metallic complexes have problems related to their fast excretion [7]. In terms of targeting and adding additional imaging modes, the use of low molecular weight lanthanide complexes is limited by high synthetic demand and the possibility of undesirable side reactions occurring during the synthesis. For these reasons, paramagnetic contrast agent research has focused on the development of nanoparticulate forms over the last few years $[8,9]$. Paramagnetic nanoparticles present several advantages over traditional coordination complexes. Composition is readily tuneable as is size and shape. 
Magnetic characteristics are improved by geometric local density effects rendering markedly higher $T_{1}$ and/or $T_{2}$ relaxometric values than the corresponding coordination complexes. In addition, control over associated pharmacokinetics enables an increase in blood circulation time [10]. Ultimately, most nanoparticulate platforms are cleared by the reticuloendothelial system (RES) with the action of macrophages, such as Kupffer cells, generating uptake from the bloodstream to the liver and spleen. The rate of this process, known as opsonization, depends on the size of the nanoparticle and its chemical coating. Nanoparticles below 5-7 nm in diameter are able to pass through the kidney glomerulus triggering fast excretion through urine. Larger particles are excreted by the RES route with kinetics that can be tuned through the surface chemistry. The protein corona that develops on these particles during circulation is key to this and can be controlled by pegylation, for example, or a polymer coating such that blood circulation time is optimised [11]. This has a direct role in MRI acquisition, where a greater acquisition time increases signal-to-noise and consequently "image quality." Another important feature within the use of nanoparticles is their high surface-to-volume ratio, supporting a high ligand (protein, antibody, and peptide) payload as well as tuneable and potentially accessible internal volume [12]. These features enable combination with drugs such that targeted, imaging-based, diagnosis may be followed by simultaneous therapy specific to that condition, known as theranostics [13].

Many different approaches have been used to develop paramagnetic nanoparticles for MRI, a few of which will be represented herein. In general, one of two synthetic strategies is followed: (1) formation of nanoparticles with the paramagnetic ion incorporated into the nanostructured framework and (2) postfunctionalisation of the particles with a lanthanide coordination complex. The first approach has been largely based on the synthesis of stoichiometric or nonstoichiometric nanoparticulate metal oxides such as $\mathrm{Gd}_{2} \mathrm{O}_{3}, \mathrm{MnO}, \mathrm{Mn}_{3} \mathrm{O}_{4}, \mathrm{Dy}_{2} \mathrm{O}_{3}$, or $\gamma-\mathrm{Fe}_{2} \mathrm{O}_{3}$. This approach also includes $\mathrm{NaGdF}_{4}, \mathrm{KGdF}_{4}, \beta-\mathrm{NaDyF}_{4}, \mathrm{NiFe}_{2} \mathrm{O}_{4}$, and $\mathrm{ZnFe}_{2} \mathrm{O}_{4}$ nanoparticles as well as others [14-19]. The second strategy has been developed with a number of supporting nanoparticle scaffolds (silica, gold, micelles, polymers, and semiconducting quantum dots) which are subsequently doped with DTPA, DOTA, or derivatives [20-24]. This review focuses on the synthesis of $\mathrm{Gd}^{3+}, \mathrm{Mn}^{2+}, \mathrm{Dy}^{3+}$, and $\mathrm{Ho}^{3+}$ nanoparticles and their biomedical application as contrast agents for MRI and multimodal imaging.

\section{Paramagnetic Ion-Based Relaxivity}

The relaxivity value, in $\mathrm{mM}^{-1} \cdot \mathrm{s}^{-1}$, quantifies the ability of a contrast agent to promote contrast in MRI. In paramagnetic ions, two different mechanisms should be considered, both an inner-sphere and an outer-sphere mechanism, respectively:

$$
\left(\frac{1}{T_{i}}\right)_{\mathrm{p}}=\left(\frac{1}{T_{i}}\right)_{\mathrm{IS}}+\left(\frac{1}{T_{i}}\right)_{\mathrm{OS}}, \quad i=1,2 .
$$

The inner-sphere mechanism is predominant in paramagnetic contrast agents. It represents the influence of the paramagnetic ion on highly local water protons and is sensitive to the chemical water exchange between the first coordination sphere (inner-sphere) of the paramagnetic ion and bulk water. In terms of longitudinal relaxation rate, a range of different factors are considered within the innersphere contribution as described in the following equation:

$$
\left(\frac{1}{T_{1}}\right)_{\mathrm{IS}}=P_{\mathrm{m}} q\left[\frac{1}{\left(T_{1 \mathrm{~m}}+\tau_{\mathrm{M}}\right)}\right] \text {, }
$$

where $P_{\mathrm{m}}$ refers to the mole fraction of the paramagnetic ion, $q$ is the number of water molecules coordinated to the metal centre (hydration number), $T_{1 \mathrm{~m}}$ the relaxation time of the water protons bounded to the ion, and $\tau_{\mathrm{M}}$ is the bound residence lifetime. By considering equation (2) and Solomon-Bloembergen-Morgan (SBM) theory, three important parameters must be taken into consideration in agent design: hydration number $(q)$, residence lifetime $\left(\tau_{\mathrm{M}}\right)$, and the rotational correlation time $\left(\tau_{\mathrm{R}}\right)$ [25]. The hydration number is usually equal to 1 in kinetically stable lanthanide complexes though a broad range of chelate agents with larger hydration numbers (and higher longitudinal relaxivities) have also been reported [26, 27]. An increase in hydration can come with the cost of stability (either chemical or signal output) [4]. Residence lifetimes should scale inversely with strength of the magnetic field and optimal values have been found to be in the range of 1-30 ns [28]. In addition, it has been shown that $\tau_{\mathrm{R}}$ governs the relaxivity when $\tau_{\mathrm{M}}$ is in the optimal range. The best relaxometric performance is typically observed when $\tau_{\mathrm{R}}$ is the range of a few nanoseconds [29].

Gadolinium $\left(\mathrm{Gd}^{3+}\right)$ and manganese $\left(\mathrm{Mn}^{2+}\right)$ are the most used paramagnetic $T_{1}$ contrast agents for MRI. Gd ${ }^{3+}$ has 7 unpaired electrons in the $4 \mathrm{f}$ subshell and a high associated spin quantum number $(S=7 / 2) . \mathrm{Mn}^{2+}$ contains 5 unpaired electrons in its valence $\mathrm{d}$ orbitals and hence also a high spin quantum number $(S=5 / 2)$. Both of them present high magnetic moments, symmetric orbital ground states, large longitudinal electronic relaxation times $\left(\sim 10^{-8} \mathrm{~s}\right)$, and fast water exchange kinetics [30, 31].

Although paramagnetic ions are more commonly used as $T_{1}$ contrast agents, there are examples, such as $\mathrm{Dy}^{3+}$ and $\mathrm{Ho}^{3+}$, which present notable $\mathrm{T}_{2}$ contrast. In contrast to $\mathrm{Mn}$ and $\mathrm{Gd}, \mathrm{Dy}^{3+}$ and $\mathrm{Ho}^{3+}$ have highly anisotropic ground states with substantial spin-orbit and Zeeman effects [32]. Therefore, these ions show very short electronic relaxation times $\left(\sim 10^{-13} \mathrm{~s}\right)$ that are accompanied by high effective magnetic moment $\left(\mu_{\text {eff }} \mathrm{Dy}^{3+}=10.6 \mu \mathrm{B}\right)$. Due to these properties, $\mathrm{Dy}^{3+}$ and $\mathrm{Ho}^{3+}$ coordination complexes are found to affect primarily the transversal relaxivity $\left(T_{2}\right.$ contrast) with relaxivities increasing with magnetic field strength by a Curie relaxation mechanism. The latter points to facilitating an application of $\mathrm{Dy}^{3+} / \mathrm{Ho}^{3+}$ molecular complexes in ultrahigh field MRI $[33,34]$.

It has been reported that the inner-sphere contribution governs the transverse relaxation of bulk water in these complexes where slow water exchange results in better 
relaxivities $[35,36]$. Very recently, it has been demonstrated that the incorporation of Dy-DOTA complexes into silica nanoparticles changes the relaxation mechanism towards that associated with an enhanced Curie outer-sphere contribution [20].

\section{Paramagnetic Nanoparticles}

A very broad range of nanoparticulate MRI contrast agents have been reported. This review will focus on a few of these (Table 1), namely, those associated with the paramagnetic ions $\mathrm{Gd}^{3+}, \mathrm{Mn}^{2+}, \mathrm{Dy}^{3+}$, and $\mathrm{Ho}^{3+}$, since they have been extensively studied and often show striking MRI performance.

3.1. Gadolinium. A broad range of approaches have been applied to the incorporation of Gd chelates into nanoparticles, some of which are included here, since they enable high levels of chemical tailoring [70]. Of them, gadoliniumdoped silica nanoparticles have been extensively reported. A study by Rieter et al., for example, utilised a luminescent $\left[\mathrm{Ru}(\mathrm{bpy})_{3}\right] \mathrm{Cl}_{3}$ core to which a coating of a silylated $\mathrm{Gd}$ complex was applied [37]. This produced stable particles with $r_{1}$ values markedly greater than conventional molecular Gd chelates. This work was then taken further to produce mesoporous silica nanoparticles (MSNs) with even higher relaxivity values in an approach that has subsequently been adopted by many research groups [38]. Other work has demonstrated that the location of the Gd chelate within the MSNs greatly influences its relaxometric properties. The highest relaxivities have been specifically reported to occur when synthesis is by a long delay co-condensation process with $r_{1}$ value of $33.6 \pm 1.3 \mathrm{mM}^{-1} \cdot \mathrm{s}^{-1}$, higher than any previously reported Gd-DOTA silica nanoparticles and 20 times larger than free Gd-DOTA (Figure 1) [39]. These particles were then biotinylated showing that the large relaxivity of the particles was essentially unchanged on external biomodification but was then reversibly gateable on subsequent protein recognition [72].

Graphene oxide (GO) has also been used as a scaffold to integrate Gd-DOTA moieties. In one study, GO was first pegylated, functionalised with DOTA, and then metallated with $\mathrm{Gd}^{3+}$. These nanoparticles presented a large $r_{1}$ value of $14.2 \mathrm{mM}^{-1} \cdot \mathrm{s}^{-1}$ measured at $11.7 \mathrm{~T}$ [41]. Another interesting scaffold for Gd-DOTA is the use of the tobacco mosaic virus (TMV). TMV is a rod-like plant virus formed by 2130 identical coat proteins assembled into a $300 \times 18 \mathrm{~nm}$ hollow tube with a $4 \mathrm{~nm}$ pore channel. Gd-DOTA was loaded into the interior channel by a copper-catalysed azide-alkyne cycloaddition reaction yielding $r_{1}=10.9 \mathrm{mM}^{-1} \cdot \mathrm{s}^{-1}$. Surprisingly, this relaxivity increased to $29.7 \mathrm{mM}^{-1} \cdot \mathrm{s}^{-1}$ when the surface of the TMV was functionalised with silica [42].

In recent work, cerium oxide nanoparticles have been utilised to produce Gd-cerium nanoparticles with antioxidant capabilities. These nanoparticles, between 3 and $5 \mathrm{~nm}$ in size, rendered longitudinal relaxivities around $7-13 \mathrm{mM}^{-1} \cdot \mathrm{s}^{-1}[40] . \mathrm{Gd}^{3+}$-impregnated nanodiamonds have also been used to produce CAs. These particles have been synthesised via an unusual detonation synthesis where an oxygen deficient trinitrotoluene/1,3,5-trinitroperhydro1,3,5-triazine (TNT/RDX) mixture is detonated under an inert atmosphere. The nanodiamonds, formed in the early stages of the detonation under high pressure, reportedly are $4-5 \mathrm{~nm}$ in size with a narrow size distribution. These were then modified with $\mathrm{Gd}^{3+}$ at the surface carboxylic groups generating unprecedented transverse relaxivity $\left(r_{2}=332 \mathrm{mM}^{-1} \cdot \mathrm{s}^{-1}\right)$ and corresponding $r_{1}=33.4 \mathrm{mM}^{-1} \cdot \mathrm{s}^{-1}$; the relaxivity mechanisms that are responsible for this high $r_{2}$ value warrant further analysis [43]. Another interesting example is a report of the synthesis of protein-based nanocages. These were further functionalised with maleimide-DTPA- $\mathrm{Gd}^{3+}$ using a cysteine residue of the protein with the relaxometric properties analysed for four nanocages with different sizes (from 16.8 to $37.1 \mathrm{~nm}$ ). The data revealed that higher $r_{1}$ values (up to $47 \mathrm{mM}^{-1} \cdot \mathrm{s}^{-1}$ at $1.5 \mathrm{~T}$ ) were obtained in larger nanocages due to the reduction in the tumbling rate of associated water molecules [44].

Gadolinium oxides are the most utilised alternatives to Gd chelates, where it has been found that decreasing particle diameter results in a progressive trend towards higher relaxivities. For instance, Park et al. showed that the highest relaxivities were obtained for nanoparticles synthesised with an average diameter of $d=1-2.5 \mathrm{~nm}$ [15]. It should be noted, however, that ultrasmall $\mathrm{Gd}_{2} \mathrm{O}_{3}$ have been found to form deposits in the brain and consequently there is a compromise between limiting the toxicity of the particles while maximising imaging potency. A study by Yin et al. produced silica nanoparticles coated in a $\mathrm{Gd}_{2} \mathrm{O}_{3}$ nanoshell of varying thicknesses. By systematically changing the thickness of the silica shell, the variations in relaxivity values could be investigated and demonstrated that a thinner shell resulted in larger $r_{1}$ values [47].

A broad number of dual modal paramagnetic particle systems have been developed [73]. $\mathrm{Gd}_{2} \mathrm{O}_{3}$ nanoparticles for fluorescence/MR imaging have, for example, been reported and doped with $\mathrm{Eu}^{3+}$ to produce $\mathrm{Gd}_{2} \mathrm{O}_{3}: \mathrm{Eu}^{3+}$ particles. Fluorescence imaging here mediated by $\mathrm{Gd}^{3+}$ absorbing a photon and moving to a ${ }^{6} I_{\mathrm{J}}$ excited state. Energy transfer between this state to the highly unstable ${ }^{5} D_{0}$ state of $\mathrm{Eu}^{3+}$ is accompanied by the emission of a photon on which the electrons return to the ground state of $\mathrm{Eu}^{3+}$. This coupled with a high $r_{1}=34.3 \mathrm{mM}^{-1} \cdot \mathrm{s}^{-1}$ results in an efficient bimodal imaging probe (Figure 2) [48]. $\mathrm{CuInS}_{2} / \mathrm{ZnS}$ quantum dots have also been reported as good candidates for fluorescence/ MRI bimodal imaging. These QDs were conjugated with a derivative compound of DTPA for further chelation with $\mathrm{Gd}^{3+}$. The composition of these QDs enhanced near-infrared fluorescence (NIRF) and MR imaging with a moderate $r_{1}=9.91 \mathrm{mM}^{-1} \cdot \mathrm{s}^{-1}[49]$. A recent approach has described the use of carbon dots (CDs) decorated with $\mathrm{Gd}^{3+}$ for fluorescence/MRI. In this work, CDs with surface carboxylic groups were obtained via a microwave synthesis. $\mathrm{Gd}^{3+}$ was then used to mediate a spherical assembly of the CDs by intercluster electrostatic linkages $\left(-\mathrm{COO}^{-}-\mathrm{Gd}^{3+}{ }_{-}^{-} \mathrm{OOC}\right)$. This formulation showed a fluorescence enhancement with increasing $\mathrm{Gd}^{3+}$ concentration and a high $r_{1}$ value of $32.1 \mathrm{mM}^{-1} \cdot \mathrm{s}^{-1}[50]$. 
TABLE 1: Examples of nanoparticle-based paramagnetic contrast agents for magnetic resonance imaging included in this review.

\begin{tabular}{|c|c|c|c|c|c|}
\hline Material & Size $(\mathrm{nm})$ & $\begin{array}{c}r_{1} \\
\left(\mathrm{mM}^{-1} \cdot \mathrm{s}^{-1}\right)\end{array}$ & $r_{2}\left(\mathrm{mM}^{-1} \cdot \mathrm{s}^{-1}\right)$ & $\begin{array}{l}\text { Magnetic field } \\
\text { (T) }\end{array}$ & Reference \\
\hline Gd-Si-DTTA & 37 & 19.7 & 60.0 & 3 & [37] \\
\hline MSN-DTTA-Gd & 75 & 28.8 & 65.5 & 3 & {$[38]$} \\
\hline Gd-DOTA-MSNs & $66.3 \pm 6.6$ & $33.6 \pm 1.3$ & - & 7 & [39] \\
\hline $\mathrm{CeOx}: \mathrm{Gd} 9 \%$ & 3.8 & 13.4 & 25.8 & 1.41 & {$[40]$} \\
\hline GO-DOTA-Gd & $20-50$ & 14.2 & - & 11.7 & {$[41]$} \\
\hline iGd-TMV-Si & $\begin{array}{c}300 \times 18 \mathrm{~nm}, 4 \mathrm{~nm} \text { internal } \\
\text { channel }\end{array}$ & 29.7 & - & 1.41 & {$[42]$} \\
\hline Gd-DND & 4.9 & 33.4 & 332.0 & 8 & {$[43]$} \\
\hline Hsp DTPA-Gd nanocage & 37.1 & 47.4 & - & 1.5 & {$[44]$} \\
\hline $\operatorname{DOTA}(\mathrm{Gd})-\mathrm{Fe} @ \mathrm{Fe}_{3} \mathrm{O}_{4}$ & 258 & 7.2 & 109.4 & 0.5 & {$[45]$} \\
\hline Gd-M-dots & 14.58 & 23.4 & 123.3 & 3 & {$[46]$} \\
\hline $\mathrm{Gd}_{2} \mathrm{O}_{3}$ & 1.0 & 9.9 & 10.5 & 1.5 & {$[15]$} \\
\hline Silica- $\mathrm{Gd}_{2} \mathrm{O}_{3}$ & 91.5 & 30.8 & - & 0.55 & [47] \\
\hline $\mathrm{Gd}_{2} \mathrm{O}_{3}: \mathrm{Eu}^{3+}$ & $7.4 \pm 0.3$ & 34.3 & - & 3 & {$[48]$} \\
\hline QDs@DTDTPA-Gd & $24.7 \pm 2.7$ & 9.9 & - & 3 & [49] \\
\hline A-C-dots@Ce6 & $98 \pm 10$ & 32.1 & - & 3 & {$[50]$} \\
\hline GBCAs-BP & 70 & 15.4 & 73.5 & 3 & {$[51]$} \\
\hline $\mathrm{GDO}(\mathrm{Gd}+\mathrm{Dy})$ & 1.0 & 6.0 & 40.0 & 1.5 & {$[52]$} \\
\hline PEG-MnO & 1.9 & 12.9 & 60.3 & 3 & [53] \\
\hline $\mathrm{MnO}$ & 7 & 0.4 & 1.7 & 3 & {$[16]$} \\
\hline $\mathrm{Mn}_{3} \mathrm{O}_{4} @ \mathrm{CF}$ & $\sim 70$ & 3.5 & - & 1.41 & {$[17]$} \\
\hline $\mathrm{MnIO}$ & 17.3 & $57.8 \pm 6.5$ & $306.3 \pm 15.2$ & 0.5 & {$[54]$} \\
\hline OA-PL-HMON & - & 1.1 & 9.2 & 3 & [55] \\
\hline NCP@peg-AA & $78.6 \pm 5.4$ & 11.6 & 19.7 & 3 & {$[56]$} \\
\hline NPs-dopa-PEG-DOTA/RGD & $26.4 \pm 7.5$ & - & 267.5 & 7 & [57] \\
\hline $\begin{array}{l}{ }^{64} \mathrm{Cu}-\mathrm{NOTA}-\mathrm{FA}-\mathrm{FI}-\mathrm{PEG} \text {-PEI-Ac- } \\
\mathrm{Mn}_{3} \mathrm{O}_{4}\end{array}$ & $476.5 \pm 13.5$ & 1.0 & - & 0.5 & {$[58]$} \\
\hline $\mathrm{Mn}-\mathrm{LDH}$ & $48.0 \pm 1.8$ & $\begin{array}{l}9.5 \text { at } \mathrm{pH} 5.0 \\
1.2 \text { at } \mathrm{pH} 7.4\end{array}$ & - & 16.4 & {$[59]$} \\
\hline $\mathrm{Fe}_{3} \mathrm{O}_{4} @ \mathrm{C} @ \mathrm{MnO}_{2}$ & 150 & $\begin{array}{c}5.3 \text { at } \mathrm{pH} 5 \\
2.2 \text { at } \mathrm{pH} 7.4\end{array}$ & $\begin{array}{l}364.2 \text { at } \mathrm{pH} 5 \\
442.4 \text { at } \mathrm{pH} 7.4\end{array}$ & 3 & {$[60]$} \\
\hline MnO@Au NCs & $45.0 \pm 5.1$ & $\begin{array}{l}2.4 \text { at } \mathrm{pH} 5.4 \\
1.2 \text { at } \mathrm{pH} 7.4\end{array}$ & - & 7 & {$[61]$} \\
\hline Dy-MSNs-L & $166.2 \pm 1.9$ & - & $143.5 \pm 8.2$ & 11.7 & {$[20]$} \\
\hline Dy(DOTA)-Cy7.5-TMV-PEG-DGEA & $\begin{array}{c}300 \times 18 \mathrm{~nm}, 4 \mathrm{~nm} \text { internal } \\
\text { channel }\end{array}$ & - & 399.0 & 9.4 & {$[62]$} \\
\hline $\mathrm{DyF}_{3}$ & 100.35 & 0.9 & 380.4 & 9.4 & {$[63]$} \\
\hline $\mathrm{D}_{2} \mathrm{O}_{3}$ (D-glucuronic acid coating) & 3.2 & 0.008 & 65.0 & 1.5 & {$[18]$} \\
\hline $\mathrm{NaDyF}_{4}$ & 20.3 & 0.3 & 101.0 & 9.4 & {$[19]$} \\
\hline Dy-doped $\mathrm{MnCO}_{3}$ & $9.27 \pm 0.72$ & 4.5 & - & 7 & {$[64]$} \\
\hline $\mathrm{Dy}_{2} \mathrm{O}_{3}: \mathrm{Tb}^{3+}$ & $3.0 \pm 0.3$ & - & 2.2 & 7 & {$[65]$} \\
\hline PEG-NaGdF 4 :Dy & - & 5.2 & 10.6 & 9.4 & {$[66]$} \\
\hline $\mathrm{SiO}_{2} @ \mathrm{Gd}_{2} \mathrm{O}_{3}: \mathrm{Dy}^{3+}$ & 101.5 & 30.2 & - & 0.55 & [67] \\
\hline $\mathrm{NaHoF}_{4}$ & 28.9 & 0.6 & 222.6 & 7 & {$[68]$} \\
\hline PEG- $\mathrm{Ho}_{2} \mathrm{O}_{3}$ & $80-90$ & - & 23.5 & 1.5 & [69] \\
\hline $\mathrm{HoF}_{3}$ & 94.3 & 0.6 & 608.4 & 9.4 & [63] \\
\hline
\end{tabular}

A dual MR/CT imaging agent based on surface functionalised bisphosphonate (BP) gadolinium oxide nanoparticles has been developed. $\mathrm{Gd}_{2} \mathrm{O}_{3}$ nanoparticles were synthesised via the polyol method and encapsulated into a mesoporous silica shell by addition of glycidyloxipropyl trimethoxysilane (GPTES). The final formulation presented an $r_{1}=15.41 \mathrm{mM}^{-1} \cdot \mathrm{s}^{-1}$ with $r_{2} / r_{1}=4.77$ at $3 \mathrm{~T}$ [51].

In addition to contrast agents enabling multiple imaging modalities, dual $T_{1}-T_{2}$ contrast agents can provide enhanced MRI imaging capabilities. Though it is sequence dependent, $T_{2}$ agents are, in general, natively disadvantaged since negative contrast generated by the contrast agent can easily be confused with natural artefacts coming from calcification or internal bleeding [74]. One approach providing $T_{1}-T_{2}$ contrast reported by Tirusew et al. used mixed Gd-Dy oxide nanoparticles [52]. Both gadolinium and dysprosium have high magnetic moments with the former promoting a shortening of longitudinal relaxation and dysprosium promoting the transverse relaxation. In an alternative approach, iron oxide nanoparticles were used instead of dysprosium to enhance $T_{2}$ contrast. In recent work, for example, Gd-labelled $\mathrm{Fe} @ \mathrm{Fe}_{3} \mathrm{O}_{4}$ particles have been reported with relaxivity values of $r_{1}=7.2 \mathrm{mM}^{-1} \cdot \mathrm{s}^{-1}$ and $r_{2}=109.4 \mathrm{mM}^{-1} \cdot \mathrm{s}^{-1}$ at $0.5 \mathrm{~T}$ [45]. Another example utilises 

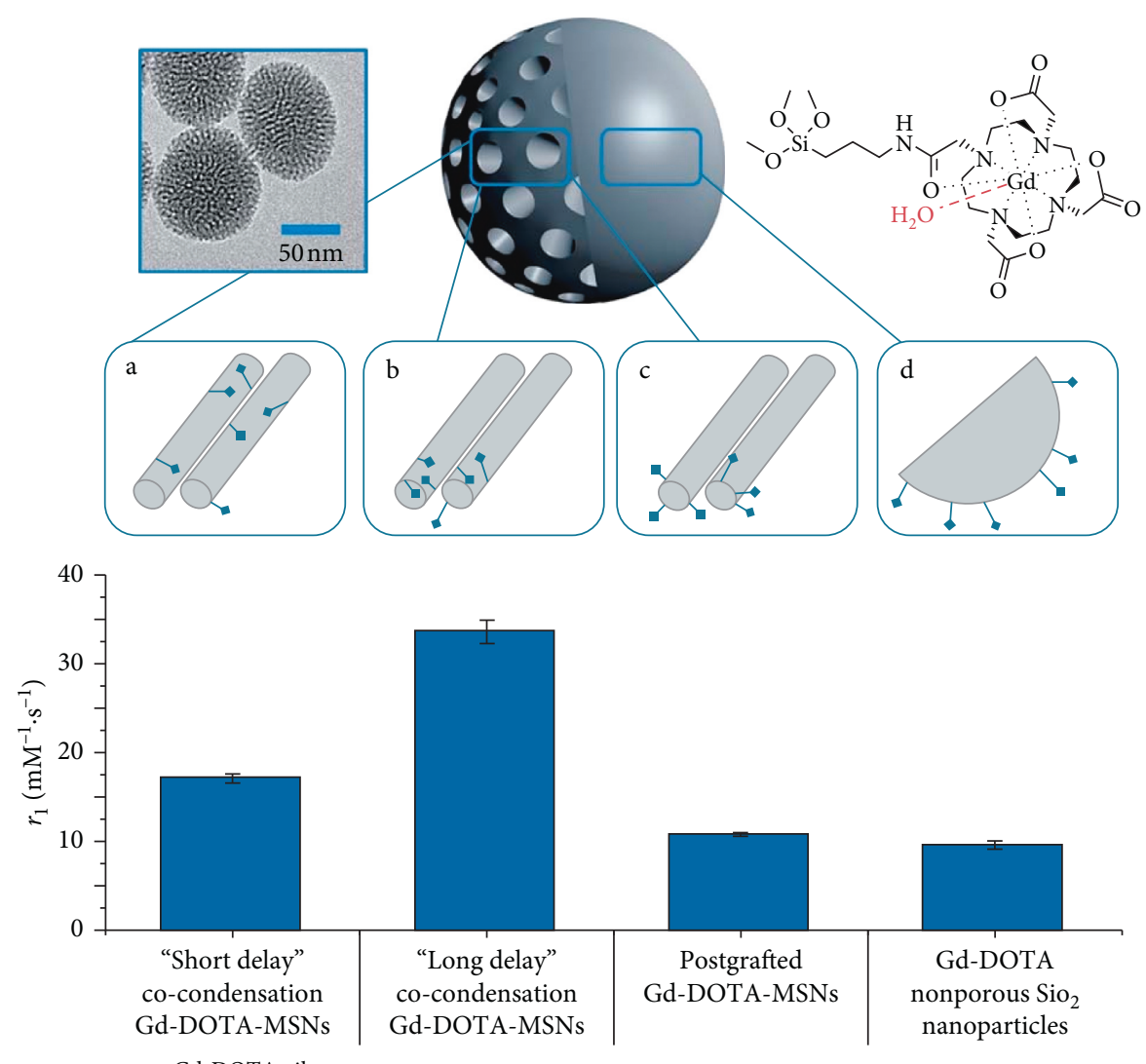

Figure 1: Typical transmission electron microscope image and schematic representation of Gd-DOTA-MSNs (66.3 $\pm 6.6 \mathrm{~nm})$ prepared using (a) "short delay" co-condensation, where functionalities are internalised deeply in the structure $\left(r_{1}=17.14 \pm 0.49 \mathrm{mM}^{-1} \cdot \mathrm{s}^{-1}\right),(\mathrm{b})$ "long delay" co-condensation, where functionalities are internalised nearer to the porous openings $\left(r_{1}=33.57 \pm 1.29 \mathrm{mM}^{-1} \cdot \mathrm{s}^{-1}\right)$, and $(\mathrm{c})$ postgrafting, where functionalities are loaded on external surfaces $\left(r_{1}=10.77 \pm 0.22 \mathrm{mM}^{-1} \cdot \mathrm{s}^{-1}\right)$. (d) Postgrafted Gd-DOTA-non-porous silica nanoparticles $\left(r_{1}=19.56 \pm 0.47 \mathrm{mM}^{-1} \cdot \mathrm{s}^{-1}\right)$ (reproduced from [71]).

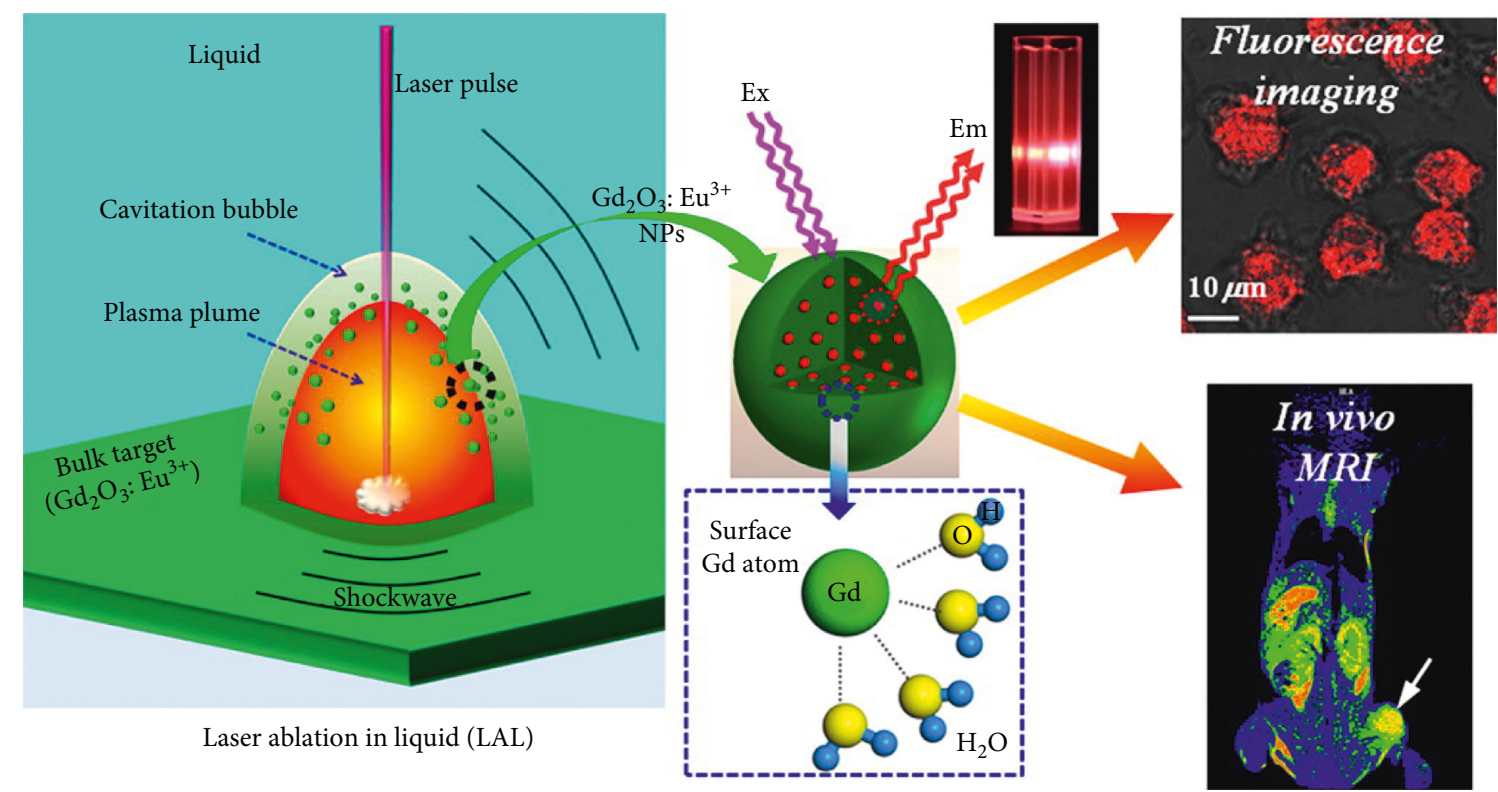

FIGURE 2: Figure illustrating the dual-modal imaging properties of $\mathrm{Gd}_{2} \mathrm{O}_{3}: \mathrm{Eu}^{3+}$ nanoparticles (reprinted (adapted) with permission from $[48])$. 
biologically inspired ultrasmall $(<10 \mathrm{~nm})$ melanin nanoparticles loaded with Gd-DOTA as a $T_{1}-T_{2}$ dual-modal contrast agent. One of the active components, melanin, is a biological pigment that is paramagnetic in nature and chelates metal ions very strongly. Its use has thus been proposed as a promising alternative to traditional iron oxide or silica-based particles [46].

3.2. Manganese. Manganese nanoparticles have been extensively researched as possible $T_{1}$ contrast agents with reduced toxicity (compared to that of gadolinium) but however suffer from low native $r_{1}$ relaxivities [53, 75]. Much effort has been invested in increasing relaxivity and biocompatibility through the use of derived nanoparticulate systems. For instance, $\mathrm{MnO}$ nanoparticles have been encapsulated in polyethylene glycol showing no significant toxicity [16]. More recently, PEG-functionalised $\mathrm{Mn}_{3} \mathrm{O}_{4}$ nanoparticles have been encapsulated in a mesoporous, biocompatible carbon framework, with the latter enabling the water access required while apparently reducing $\mathrm{Mn}$ cation loss [17]. Other works conducted by Zhao et al. substituted $\mathrm{Fe}^{2+}$ ions on the surface of magnetite particles with $\mathrm{Mn}^{2+}$ to produce particles with $T_{1}$-weighted imaging capabilities [54]. On increasing the extent of doping of $\mathrm{Mn}^{2+}$ on the surface, an element with both a longer electronic relaxation time and greater paramagnetism than $\mathrm{Fe}^{2+}$, there was a corresponding increase in $r_{1}$.

Hollow $\mathrm{Mn}_{3} \mathrm{O}_{4}$ nanoparticles have been used in a study of the effect of surface functionalisation on relaxometric properties. It was observed, for example, that, with carboxylic acid functionalised ligands, there was a corresponding increase in $r_{1}$. This was proposed to be due to the induction of ferromagnetic spins between free surface spins [55]. Coordination polymers (NCP) of nanometric size $(78.6 \pm 5.4 \mathrm{~nm})$ have been loaded with $\mathrm{Mn}^{2+}$ to produce efficient $T_{1}$ contrast agents. In this case, organic bridging ligands are used to produce a self-assembly process with $\mathrm{Mn}^{2+}$. These nanoparticles displayed high Mn loading of up to $13.3 \pm 4$ wt. $\%$ with a maximum $r_{1}$ value of $11.6 \mathrm{mM}^{-1} \cdot \mathrm{s}^{-1}$. The increase in the relaxivity was assigned to a reduction in the tumbling rates [56].

There has been a growing interest in the development of environmentally responsive MR agents [76]. One major class of these are $\mathrm{pH}$ responsive contrast agents which offer potential value in resolving the low $\mathrm{pH}$ microenvironment associated with tumour tissue [76]. Manganese-based double-layered hydroxide nanoparticles were the first reported ultrasensitive $\mathrm{pH}$-responsive $\mathrm{Mn}$-based contrast agent for $T_{1}$ MRI imaging, showing a 6-fold increase in longitudinal relaxivity values in acidic media $(\mathrm{pH}=5)$ than at $\mathrm{pH}=7.4$, a switch assigned to the unique structure of $\mathrm{Mn}$ ions in the double-layered hydroxide [59]. Another reported $\mathrm{pH}$ responsive nanoparticulate example has been the synthesis of $\mathrm{Fe}_{3} \mathrm{O}_{4} @ \mathrm{C} @ \mathrm{MnO}_{2}$ nanoparticles. Here, iron oxide nanoparticles were coated with a carbon layer and reacted with $\mathrm{KMnO}_{4}$ to produce $\mathrm{MnO}_{2}$ nanosheets on the outer carbon shells. In a protic environment, these $\mathrm{MnO}_{2}$ nanosheets are reduced to $\mathrm{Mn}^{2+}$ The increased concentration of paramagnetic $\mathrm{Mn}^{2+}$ ions in solution is accompanied by a corresponding increase in $T_{1}$ relaxation [60]. Manganese monoxide nanocomposites functionalised with porous gold nanoclusters have also been used as $\mathrm{pH}$-responsive probes. In this work, it was suggested that the gold nanoclusters sterically hinder the release $\mathrm{Mn}^{2+}$ from the particles, consequently providing delayed $T_{1}$ contrast and a longer diagnostic window. They also allow the system to function as a multimodal probe with photoacoustic and X-ray CT imaging modalities additionally supported [61].

3.3. Dysprosium. Dysprosium is one possible alternative to conventional gadolinium-based contrast agents and acts as an effective $T_{2}$ contrast agent through its high magnetic moment (the largest of the lanthanides) and short $\left(\sim 10^{-13} \mathrm{~s}\right)$ electronic relaxation time. Many approaches have been employed to produce dysprosium-modified nanoparticles, most recently MSNs that incorporate DyDOTA chelates in the outer pore channel producing particles with high $r_{2}$ values of $143.5 \pm 8.2 \mathrm{mM}^{-1} \cdot \mathrm{s}^{-1}$ at $11.7 \mathrm{~T}$, some 20 times larger in magnitude than the molecular analogue [20]. Even higher $T_{2}$ relaxivities have been reported by loading Dy-DOTA chelates into the cavity of the tobacco mosaic virus $\left(r_{2}\right.$ values of $326 \mathrm{mM}^{-1} \cdot \mathrm{s}^{-1}$ at $7 \mathrm{~T}$ and $399 \mathrm{mM}^{-1} \cdot \mathrm{s}^{-1}$ at $\left.9 \mathrm{~T}\right)$ [62]. Dysprosium oxide nanoparticles and dysprosium fluoride have also been proposed as promising agents. For example, González-Mancebo et al. produced $\mathrm{DyF}_{3}$ rhombusshaped nanoparticles with an average size of $110 \times 50 \mathrm{~nm}$. These nanoparticles present a remarkable $r_{2}$ of $380.4 \mathrm{mM}^{-1} \cdot \mathrm{s}^{-1}$ when measured at $9.4 \mathrm{~T}$, ascribed to strong outer-sphere effects where the diffusion correlation time $\left(\tau_{D}\right)$ is affected by the effective radius of the nanoparticles [63]. Dysprosium oxide nanoparticles and dysprosium hydroxide nanorods have also been described as good candidates for $T_{2}$ contrast agents. Research by Kattel et al. synthesised d-glucuronic acid-coated ultrasmall $\mathrm{Dy}_{2} \mathrm{O}_{3}$ nanoparticles with an average size of $3.2 \mathrm{~nm}$ and $\mathrm{Dy}(\mathrm{OH})_{3}$ nanorods with an average size of $20 \times 300 \mathrm{~nm}$. The first formulation showed an $r_{2}=65.0 \mathrm{mM}^{-1} \cdot \mathrm{s}^{-1}$ whilst the nanorods possessed a higher value $\left(r_{2}=181.57 \mathrm{mM}^{-1} \cdot \mathrm{s}^{-1}\right.$ at $\left.1.5 \mathrm{~T}\right)$ due to their greater size [18]. $\beta-\mathrm{NaDyF}_{4}$ nanoparticles have shown potential as ultrahigh field magnetic resonance imaging (9.4 T) agents with high $r_{2}$ values [19]. Another formulation based on the synthesis of $\mathrm{MnCO}_{3}$ nanoparticles doped with Dy exhibited reported $r_{1}$ values higher than those typical of MnO NPs [64].

There are numerous reports of dual-modal contrast nanoparticulate agents containing dysprosium. $\mathrm{Tb}^{3+}$-doped $\mathrm{Dy}_{2} \mathrm{O}_{3}$ nanoparticles have, for example, been reported to possess both MRI and optical imaging modalities since $\mathrm{Tb}^{3+}$ emits across the range of $489 \mathrm{~nm}$ to $619 \mathrm{~nm}$, the brightest region being $\sim 545 \mathrm{~nm}$ (green) [65]. PEGylated $\mathrm{NaGdF}_{4}$ : Dy nanoprobes as both dual-modal $T_{1}-T_{2}$ and MRI/CT agents were produced by Jin et al. $T_{1}$-weighted contrast is provided by the presence of $\mathrm{Gd}^{3+}$ ions with $T_{2}$-weighted contrast 


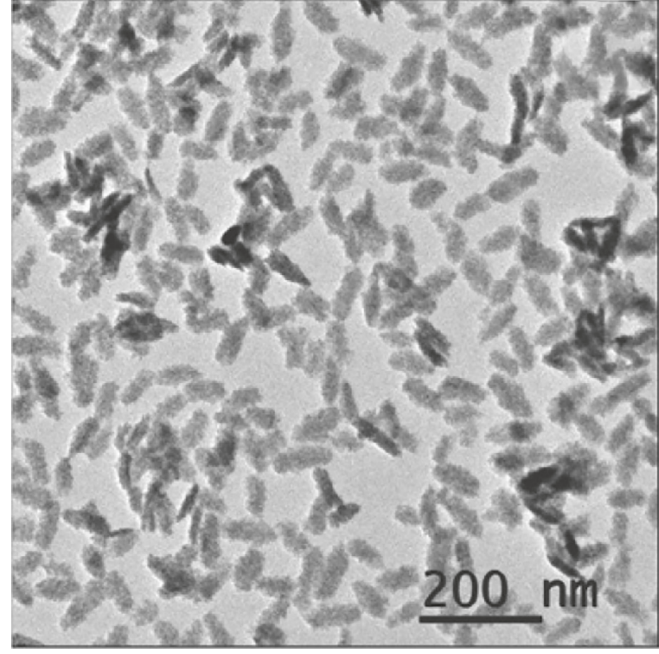

(a)

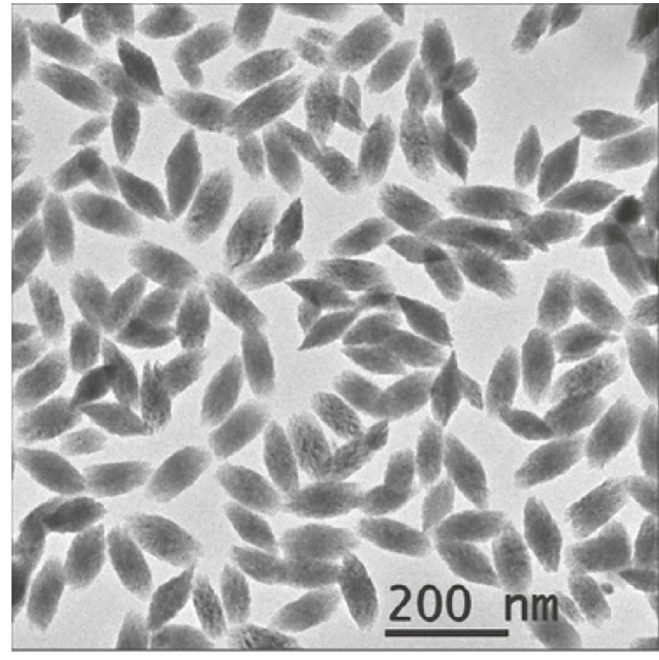

(c)

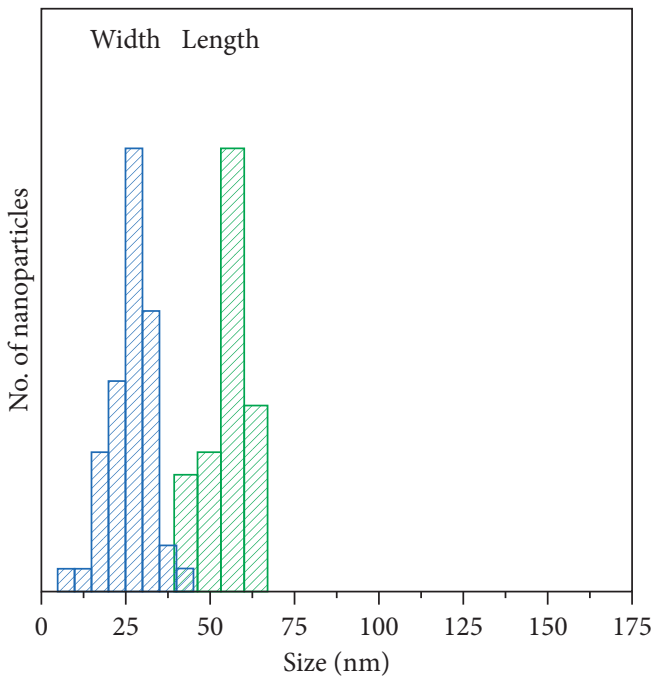

(b)

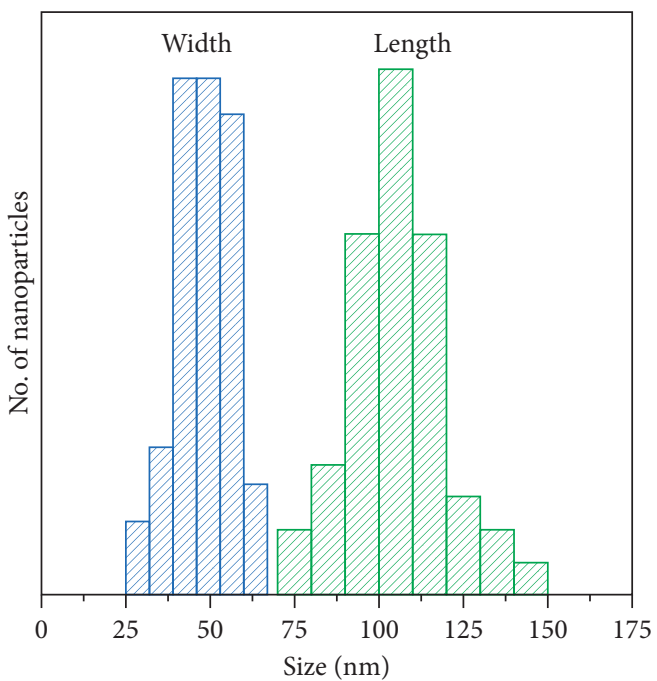

(d)

FIGURE 3: TEM images and size distribution plots obtained from TEM images of (a, b) HoF-el and (c, d) HoF-rh NPs (reprinted (adapted) with permission from [63]).

promoted by the doped $\mathrm{Dy}^{3+}$ ions, which also facilitates the use of the nanoprobe for CT imaging [66]. Dysprosium has been used to dope $\mathrm{Gd}_{2} \mathrm{O}_{3}$ nanoparticles resulting in dualmodal MR/fluorescence imaging [67]. These particles contain a silica core encapsulated by a $\mathrm{Gd}_{2} \mathrm{O}_{3}$ : $\mathrm{Dy}^{3+}$ nanoshell. Altering the thickness of this shell changed the relaxometric properties of the system with the highest $r_{1}$ values being reported for the thinnest $(2 \mathrm{~nm})$ shells.

3.4. Holmium. Holmium is another paramagnetic lanthanide with a highly effective magnetic moment and short electronic relaxation time. The first example of single $\mathrm{Ho}^{3+}-$ doped upconversion nanoparticles for $T_{2}$-weighted MRI was reported by $\mathrm{Ni}$ et al., focusing on $\mathrm{Ho}^{3+}$-doped $\mathrm{NaYbF}_{4}$ with surface phospholipid-PEGylation. Incorporation of both $\mathrm{Yb}^{3+}$ as a sensitizer and $\mathrm{Ho}^{3+}$ as an activator facilitates upconversion such that optical emission in the visible region is possible. In conjunction with efficient $r_{2}$ relaxation, this example is an effective dual-modal contrast agent [77]. $\mathrm{NaHoF}_{4}$ nanoparticles have also been shown to be effective for $T_{2}$-weighted MRI with reported values of $r_{2}=222.6 \mathrm{mM}^{-1} \cdot \mathrm{s}^{-1}$ at $7 \mathrm{~T}$ [68], as have holmium oxide nanoparticles. [69] The highest reported $r_{2}$ values for holmium, and indeed any of the examples mentioned in this review, are for rhombus-like $\mathrm{HoF}_{3}$ nanoparticles produced by González-Mancebo et al. with $r_{2}=608.4$ at $9.4 \mathrm{~T}$.

In this work, two different $\mathrm{HoF}_{3}$ formulations were synthesised by homogeneous precipitation in ethylene glycol. Particle size and shape was notably tuneable with $\mathrm{Ho}\left(\mathrm{NO}_{3}\right)_{3}$ rendering ellipsoid-like nanoparticles (socalled HoF-el) and $70 \times 30 \mathrm{~nm}$ in size (Figures $3(\mathrm{a})$ and 3(b)). An alternative with $\mathrm{Ho}\left(\mathrm{CH}_{3} \mathrm{CO}_{2}\right)_{3}$ as the precursor formed rhombus-like nanoparticles (so-called HoF-rh) with an average size of $110 \times 50 \mathrm{~nm}$ (Figures 3(c) and 


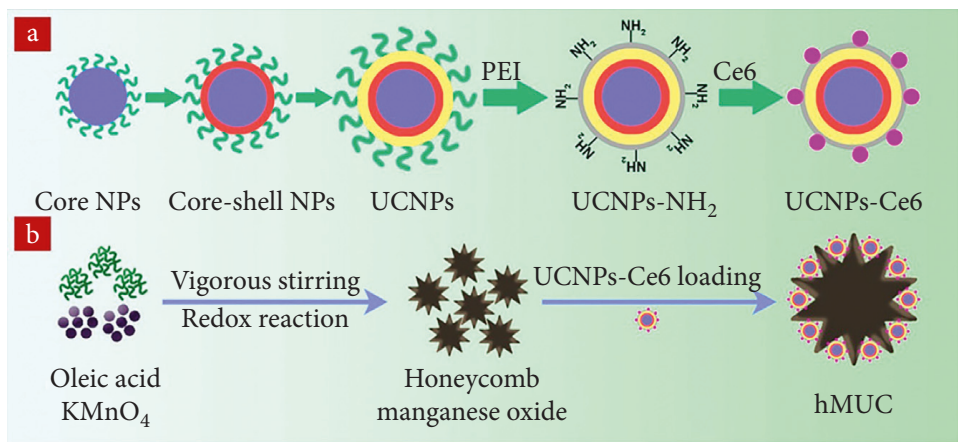

(a)
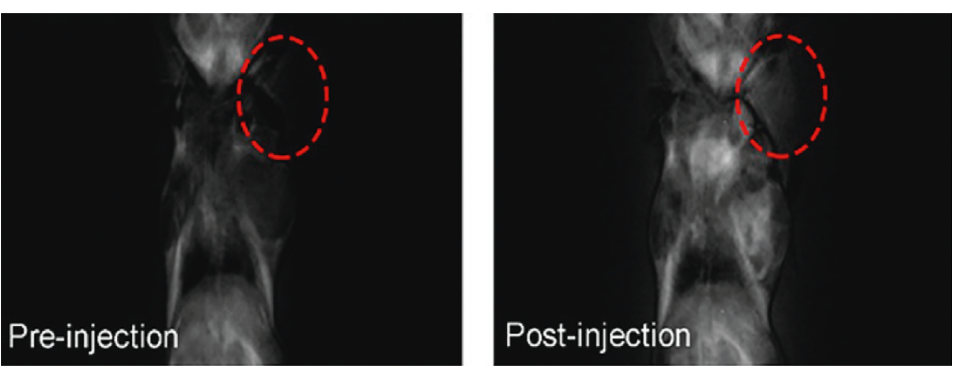

(b)

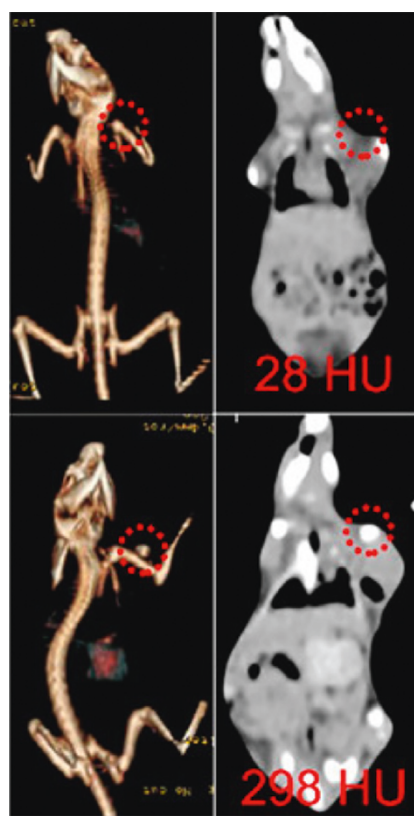

(c)

FIgURE 4: (a) Schematic illustration for the synthesis of UCNPs-Ce6 and hMUC. (b) In vivo $T_{1}$-weighted MR images of a tumour-bearing mouse before (left) and after (right) intravenous injection of hMUC. (c) In vivo CT images of a tumour-bearing mouse before (upper) and after (lower) intratumour injection (reprinted (adapted) with permission from [90]).

3(d)). Although HoF-el displayed large $r_{2}$ value of $350.0 \mathrm{mM}^{-1} \cdot \mathrm{s}^{-1}$ at high magnetic fields $(9.4 \mathrm{~T})$, an unprecedented $r_{2}$ value of $608.4 \mathrm{mM}^{-1} \cdot \mathrm{s}^{-1}$ was reported for HoF-rh indicating not only a size dependency (increased magnetisation of the larger particles) but also pronounced geometric effects [63].

\section{Multimodal Imaging and Theranostic Applications}

Paramagnetic nanoparticles have applications in responsive MRI, targeted imaging, cell tracking, multimodal imaging, and as part of a theranostic platform. Here, some relevant and interesting examples reported across the last few years are described.

Very recently, $\mathrm{Gd}^{3+}$ complexes have been integrated into protein, calcium phosphate, polymeric, gold, and bismuth based nanoparticles. These have been utilised as nanotheranostics tools for multimodal imaging and in cancer therapy but also for the chemical imaging of neurotransmitters [78-83]. In 2018, $\mathrm{Gd}_{2} \mathrm{O}_{3}$ nanoparticles were applied to the targeted imaging of integrins for cancer diagnostics, cell labelling studies, and the multimodal imaging of calcium phosphate bone cement [51, 84, 85]. $\mathrm{Gd}^{3+}$ has been immobilized into metallofullerenes for MRI and photothermal therapy at tumour sites, within cerium oxide nanoparticles (CeNP) as a promising antioxidant theranostic agent, within leukosomes with enhanced activity towards activated endothelium cells, and on carbon dots for imaging-guided radiotherapy of tumours [40, 86-88].
Liu et al. reported multifunctional redox/pH responsive $\mathrm{MnO}_{2}$ nanoparticles for cancer theranostics [89]. Based on honeycomb $\mathrm{MnO}_{2}$ nanoparticles $\left(\mathrm{hMnO}_{2}\right)$, Sun et al. have developed $\mathrm{pH} / \mathrm{H}_{2} \mathrm{O}_{2}$ responsive nanoparticles loaded with the photosensitiser chlorin e6 (Ce6). These upconverting nanoparticles, denoted as hMUC (Figure 4(a)), support high in vivo MRI $T_{1}$ contrast within tumours (Figure $4(\mathrm{~b})$ ). The presence of high Z-elements also facilitated CT imaging (Figure $4(\mathrm{c})$ ). Finally, the particles were able to produce reactive oxygen species (ROS) through action of the Ce6 photosensitiser enabling tumour treatment by photodynamic therapy (PDT) [90].

Similar methodologies have been reported in enabling the $\mathrm{pH}$ and/or redox responsive diagnosis and photodynamic therapy of tumours using $\mathrm{MnO}_{2}$ nanoparticles coupled with gold nanocages, copper sulfide nanostructures, or iron oxide nanoparticles [91-94].

Wang et al. have recently reported the synthesis of holmium-doped hollow silica nanospheres to create multifunctional theranostic nanoparticles. These were subsequently conjugated with a prostate stem cell antigen (PSCA) monoclonal antibody for targeted bimodal US/MRI of tumours as well as combined sonodynamic and hypoxia activated therapy [95]. Another application of multifunctional nanoparticles for dual-modal imaging is reported by Li et al., where ternary-doped (fluorine, ytterbium, and holmium) hydroxyapatite nanoparticles were used for multimodal imaging/tracking of hydroxyapatite in hard tissue repair [96]. Pegylated $\mathrm{NaHoF}_{4}$ nanoparticles have also been employed for single MR and MR/CT dual-modality imaging applications $[68,97]$. 
(A) Assembled TMV nanotube

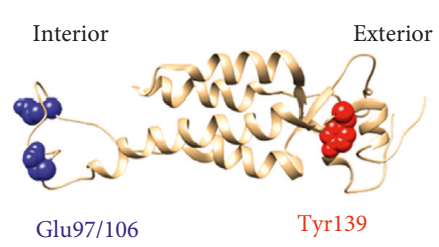

Coat protein unit

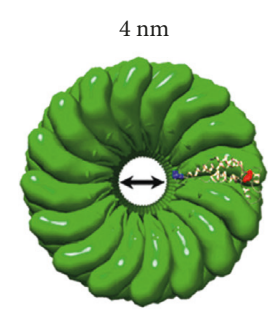

Top view

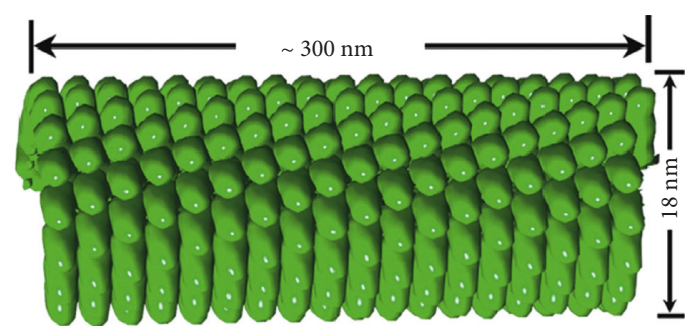

Side view

(B) Internal modification

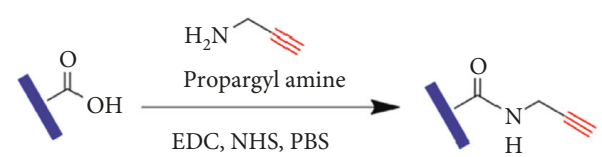

Glu97/106

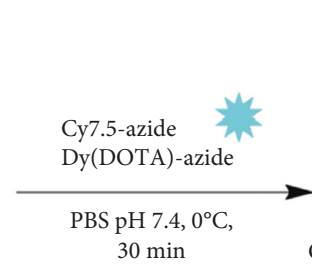

$30 \mathrm{~min}$

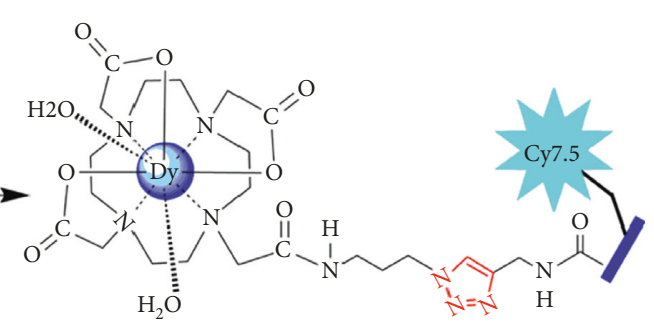

Dy-Cy7.5-TMV

(a)

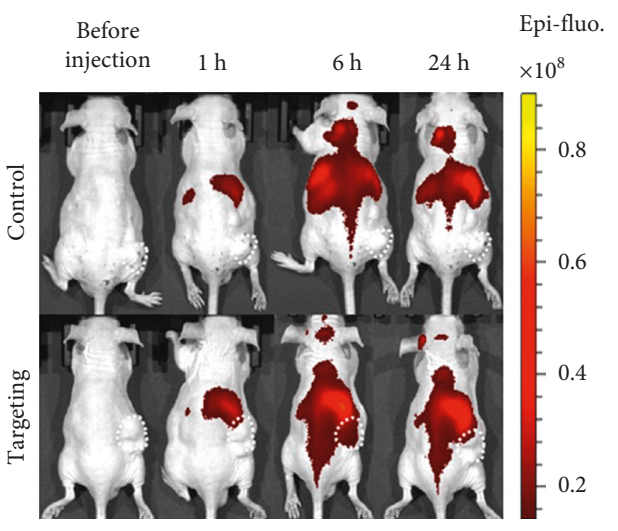

(b)

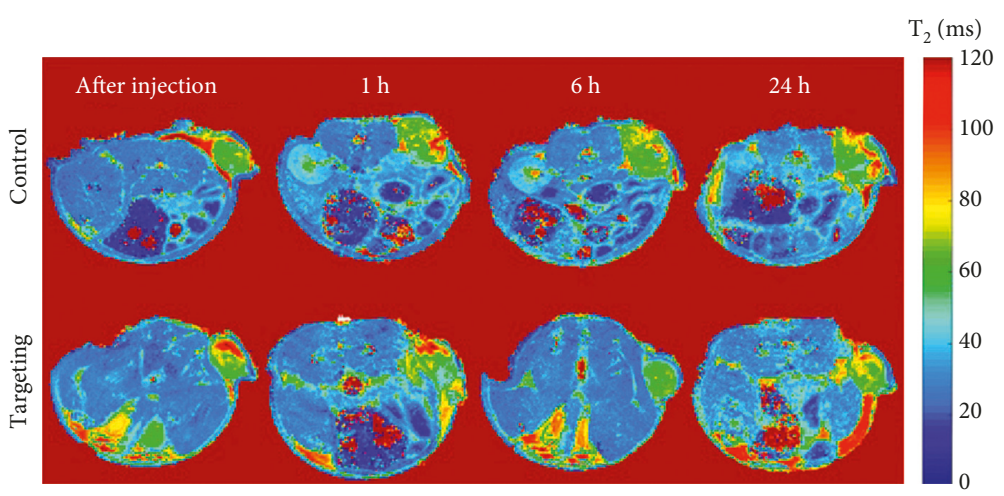

(c)

FIgURE 5: (a) Structure of the tobacco mosaic virus (TMV) nanoparticle's coat protein with surface-exposed residues highlighted as internal glutamic acid (blue) and external tyrosine (red) and the structure of the assembled capsid/strategy for internal modification. (b) Near-infrared fluorescence (NIRF) imaging of subcutaneous PC-3 ( $\alpha 2 \beta 1)$ prostate tumours in athymic nude mice $(n=3)$ before and 1,6, and $24 \mathrm{~h}$ after the intravenous injection of Dy-Cy7.5-TMV-mPEG (control group) or Dy-Cy7.5-TMV-DGEA (targeting group). (c) In vivo $T_{2}$-mapping MRI of subcutaneous PC-3 $(\alpha 2 \beta 1)$ prostate tumours in athymic nude mice $(n=3)$ obtained before and 1,6 , and $24 \mathrm{~h}$ after the intravenous injection of Dy-Cy7.5-TMV-mPEG (control group) and Dy-Cy7.5-TMV-DGEA (targeting group) (reprinted (adapted) with permission from [62]).

A notable example is reported by $\mathrm{Hu}$ et al. where dysprosium-modified tobacco mosaic virus nanoparticles were used for the bimodal MR/NIRF imaging of prostate cancer. In this work, internal glutamic acid residues were exploited to functionalise the nanoparticles with DyDOTA-azide and a NIRF dye Cy7.5-azide by a coppercatalysed azide-alkyne click chemistry cycloaddition (Figure 5(a)). Then, the external surface was conjugated with a DGEA peptide that binds to a specific integrin on the surface of PC-3 prostate cancer cells. The final formulation was able to produce targeted NIRF imaging in nude mice (Figure 5(b)), displaying strong $T_{2}$ contrast as supported by a high transverse relaxivity $\left(399 \mathrm{mM}^{-1} \cdot \mathrm{s}^{-1}\right.$ at 9.4 T) (Figure 5(c)) [62].

\section{Conclusions}

Paramagnetic contrast agents present themselves as valuable tools for a broad range of potent MRI applications. Although traditional paramagnetic coordination complexes have been extensively applied, control over both thermodynamic and kinetic stability, pharmacokinetics, biodistribution, and imaging potency is limited. There are a wide variety of accessible synthetic procedures to develop nanoparticles conjugated with paramagnetic ions with a control over composition, size, and shape. This supports facile management of stability, pharmacokinetics, and biodistribution. Associated paramagnet hydration, water exchange kinetics, or residence lifetime can be tuned, all at high levels of local 
loading. The ability to readily integrate additional imaging modes and the employment of multivalent vectors across comparatively high particle surface areas make these yet more promising. To date, these constructs have been applied to the targeted multimodal molecular imaging, of cancer, cardiovascular, and neurological diseases as well as drug delivery, photodynamic, and sonodynamic therapy. One would fully expect the chemical richness available here to be truly impactful over the next decade.

\section{Conflicts of Interest}

The authors declare that they have no conflicts of interest.

\section{References}

[1] J. V. Frangioni, "New technologies for human cancer imaging," Journal of Clinical Oncology, vol. 26, no. 24, pp. 40124021, 2008.

[2] J. Sanz and Z. A. Fayad, "Imaging of atherosclerotic cardiovascular disease," Nature, vol. 451, no. 7181, pp. 953-957, 2008.

[3] S. Geethanath and J. T. Vaughan Jr., "Accessible magnetic resonance imaging: a review," Journal of Magnetic Resonance Imaging, 2019, In press.

[4] L. M. De León-Rodríguez, A. F. Martins, M. C. Pinho, N. M. Rofsky, and A. D. Sherry, "Basic MR relaxation mechanisms and contrast agent design," Journal of Magnetic Resonance Imaging, vol. 42, no. 3, pp. 545-565, 2015.

[5] Y. Bao, J. A. Sherwood, and Z. Sun, "Magnetic iron oxide nanoparticles as $T_{1}$ contrast agents for magnetic resonance imaging," Journal of Materials Chemistry C, vol. 6, no. 6, pp. 1280-1290, 2018.

[6] Y.-D. Xiao, R. Paudel, J. Liu, C. Ma, Z.-S. Zhang, and S.-K. Zhou, "MRI contrast agents: classification and application (review)," International journal of molecular medicine, vol. 38, no. 5, pp. 1319-1326, 2016.

[7] M. Bottrill, L. Kwok, and N. J. Long, "Lanthanides in magnetic resonance imaging," Chemical Society Reviews, vol. 35, no. 6, pp. 557-571, 2006.

[8] H. B. Na and T. Hyeon, "Nanostructured $T_{1}$ MRI contrast agents," Journal of Materials Chemistry, vol. 19, no. 35, pp. 6267-6273, 2009.

[9] E. Peng, F. Wang, and J. M. Xue, "Nanostructured magnetic nanocomposites as MRI contrast agents," Journal of Materials Chemistry B, vol. 3, no. 11, pp. 2241-2276, 2015.

[10] M. J. Ernsting, M. Murakami, A. Roy, and S.-D. Li, "Factors controlling the pharmacokinetics, biodistribution and intratumoral penetration of nanoparticles," Journal of Controlled Release, vol. 172, no. 3, pp. 782-794, 2013.

[11] J.-W. Yoo, E. Chambers, and S. Mitragotri, "Factors that control the circulation time of nanoparticles in blood: challenges, solutions and future prospects," Current Pharmaceutical Design, vol. 16, no. 21, pp. 2298-2307, 2010.

[12] X. Han, K. Xu, O. Taratula, and K. Farsad, "Applications of nanoparticles in biomedical imaging," Nanoscale, vol. 11, no. 3, pp. 799-819, 2019.

[13] C. O. Silva, J. O. Pinho, J. M. Lopes, A. J. Almeida, M. M. Gaspar, and C. Reis, "Current trends in cancer nanotheranostics: metallic, polymeric, and lipid-based systems," Pharmaceutics, vol. 11, no. 1, p. 22, 2019.
[14] F. Hu and Y. S. Zhao, "Inorganic nanoparticle-based $T_{1}$ and $T_{1} / T_{2}$ magnetic resonance contrast probes," Nanoscale, vol. 4 , no. 20, pp. 6235-6243, 2012.

[15] J. Y. Park, M. J. Baek, E. S. Choi et al., "Paramagnetic ultrasmall gadolinium oxide nanoparticles as advanced $T_{1}$ MRI contrast agent: account for large longitudinal relaxivity, optimal particle diameter, and in vivo $T_{1} \mathrm{MR}$ images," $A C S$ Nano, vol. 3, no. 11, pp. 3663-3669, 2009.

[16] H. B. Na, J. H. Lee, K. An et al., "Development of a $T_{1}$ contrast agent for magnetic resonance imaging using $\mathrm{MnO}$ nanoparticles," Angewandte Chemie International Edition, vol. 46, no. 28, pp. 5397-5401, 2007.

[17] K. Deka, A. Guleria, D. Kumar et al., "Mesoporous 3D carbon framework encapsulated manganese oxide nanoparticles as biocompatible $T_{1}$ MR imaging probe," Colloids and Surfaces A: Physicochemical and Engineering Aspects, vol. 539, pp. 229-236, 2018.

[18] K. Kattel, J. Y. Park, W. Xu et al., "Paramagnetic dysprosium oxide nanoparticles and dysprosium hydroxide nanorods as $T_{2}$ MRI contrast agents," Biomaterials, vol. 33, no. 11, pp. 3254-3261, 2012.

[19] G. K. Das, N. J. J. Johnson, J. Cramen et al., "NaDyF4 nanoparticles as $T_{2}$ contrast agents for ultrahigh field magnetic resonance imaging," Journal of Physical Chemistry Letters, vol. 3, no. 4, pp. 524-529, 2012.

[20] X.-Y. Zheng, J. Pellico, A. A. Khrapitchev, N. R. Sibson, and J. J. Davis, "Dy-DOTA integrated mesoporous silica nanoparticles as promising ultrahigh field magnetic resonance imaging contrast agents," Nanoscale, vol. 10, no. 45, pp. 21041-21045, 2018.

[21] Y. Yang, S. Chen, H. Li et al., "Engineered paramagnetic graphene quantum dots with enhanced relaxivity for tumor imaging," Nano Letters, vol. 19, no. 1, pp. 441-448, 2018.

[22] L. Litti, N. Rivato, G. Fracasso et al., "A SERRS/MRI multimodal contrast agent based on naked $\mathrm{Au}$ nanoparticles functionalized with a Gd(III) loaded PEG polymer for tumor imaging and localized hyperthermia," Nanoscale, vol. 10, no. 3, pp. 1272-1278, 2018.

[23] A. Babic, V. Vorobiev, G. Trefalt et al., "MRI micelles selfassembled from synthetic gadolinium-based nano building blocks," Chemical Communications, vol. 55, no. 7, pp. 945948, 2019.

[24] I. Craciun, G. Gunkel-Grabole, A. Belluati, C. G. Palivan, and W. Meier, "Expanding the potential of MRI contrast agents through multifunctional polymeric nanocarriers," Nanomedicine, vol. 12, no. 7, pp. 811-817, 2017.

[25] A. J. L. Villaraza, A. Bumb, and M. W. Brechbiel, "Macromolecules, dendrimers, and nanomaterials in magnetic resonance imaging: the interplay between size, function, and pharmacokinetics," Chemical Reviews, vol. 110, no. 5, pp. 2921-2959, 2010.

[26] B. Zhang, L. Cheng, B. Duan et al., "Gadolinium complexes of diethylenetriamine- $N$-oxide pentaacetic acid-bisamide: a new class of highly stable MRI contrast agents with a hydration number of 3," Dalton Transactions, vol. 48, no. 5, pp. 16931699, 2019.

[27] A. Datta and K. N. Raymond, "Gd-Hydroxypyridinone (HOPO)-based high-relaxivity magnetic resonance imaging (MRI) contrast agents," Accounts of Chemical Research, vol. 42, no. 7, pp. 938-947, 2009.

[28] E. J. Werner, A. Datta, C. J. Jocher, and K. N. Raymond, "High-relaxivity MRI contrast agents: where coordination chemistry meets medical imaging," Angewandte Chemie International Edition, vol. 47, no. 45, pp. 8568-8580, 2008. 
[29] L. Granato, L. Vander Elst, C. Henoumont, R. N. Muller, and S. Laurent, "Optimizing water exchange rates and rotational mobility for high-relaxivity of a novel Gd-DO3A derivative complex conjugated to inulin as macromolecular contrast agents for MRI," Chemistry \& Biodiversity, vol. 15, no. 2, article e1700487, 2018.

[30] E. Boros, E. M. Gale, and P. Caravan, "MR imaging probes: design and applications," Dalton Transactions, vol. 44, no. 11, pp. 4804-4818, 2015.

[31] E. M. Gale, I. P. Atanasova, F. Blasi, I. Ay, and P. Caravan, "A manganese alternative to gadolinium for MRI contrast," Journal of the American Chemical Society, vol. 137, no. 49, pp. 15548-15557, 2015.

[32] M. Norek and J. A. Peters, "MRI contrast agents based on dysprosium or holmium," Progress in nuclear magnetic resonance spectroscopy, vol. 59, no. 1, pp. 64-82, 2011.

[33] L. Vander Elst, S. Zhang, A. D. Sherry, S. Laurent, F. Botteman, and R. N. Muller, "Dy-complexes as high field $T_{2}$ contrast agents," Academic Radiology, vol. 9, no. 2, pp. S297-299, 2002.

[34] G. A. Pereira, J. A. Peters, F. A. Almeida Paz, J. Rocha, and C. F. G. C. Geraldes, "Evaluation of $\left[\mathrm{Ln}\left(\mathrm{H}_{2} \mathrm{cmp}\right)\left(\mathrm{H}_{2} \mathrm{O}\right)\right]$ metal organic framework materials for potential application as magnetic resonance imaging contrast agents," Inorganic Chemistry, vol. 49, no. 6, pp. 2969-2974, 2010.

[35] L. Vander Elst, A. Roch, P. Gillis et al., "Dy-DTPA derivatives as relaxation agents for very high field MRI: the beneficial effect of slow water exchange on the transverse relaxivities," Magnetic Resonance in Medicine, vol. 47, no. 6, pp. 1121-1130, 2002.

[36] P. Caravan, M. T. Greenfield, and J. W. M. Bulte, "Molecular factors that determine Curie spin relaxation in dysprosium complexes," Magnetic Resonance in Medicine, vol. 46, no. 5, pp. 917-922, 2001.

[37] W. J. Rieter, J. S. Kim, K. M. L. Taylor et al., "Hybrid silica nanoparticles for multimodal imaging," Angewandte Chemie International Edition, vol. 46, no. 20, pp. 3680-3682, 2007.

[38] K. M. L. Taylor, J. S. Kim, W. J. Rieter, H. An, W. Lin, and W. Lin, "Mesoporous silica nanospheres as highly efficient MRI contrast agents," Journal of the American Chemical Society, vol. 130, no. 7, pp. 2154-2155, 2008.

[39] J. J. Davis, W.-Y. Huang, and G.-L. Davies, "Location-tuned relaxivity in Gd-doped mesoporous silica nanoparticles," Journal of Materials Chemistry, vol. 22, no. 43, pp. 2284822850, 2012.

[40] P. Eriksson, A. A. Tal, A. Skallberg et al., "Cerium oxide nanoparticles with antioxidant capabilities and gadolinium integration for MRI contrast enhancement," Scientific Reports, vol. 8, no. 1, p. 6999, 2018.

[41] M. Zhang, X. Liu, J. Huang et al., "Ultrasmall graphene oxide based $\mathrm{T}_{1}$ MRI contrast agent for in vitro and in vivo labeling of human mesenchymal stem cells," Nanomedicine: Nanotechnology, Biology and Medicine, vol. 14, no. 7, pp. 2475-2483, 2018.

[42] M. A. Bruckman, L. N. Randolph, N. M. Gulati, P. L. Stewart, and N. F. Steinmetz, "Silica-coated Gd(DOTA)-loaded protein nanoparticles enable magnetic resonance imaging of macrophages," Journal of Materials Chemistry B, vol. 3, no. 38, pp. 7503-7510, 2015.

[43] A. M. Panich, M. Salti, S. D. Goren et al., "Gd(III)-grafted detonation nanodiamonds for MRI contrast enhancement," Journal of Physical Chemistry C, vol. 123, no. 4, pp. 2627-2631, 2019.
[44] T. Kawano, M. Murata, J.-H. Kang et al., "Ultrasensitive MRI detection of spontaneous pancreatic tumors with nanocagebased targeted contrast agent," Biomaterials, vol. 152, pp. 37-46, 2018.

[45] K. Wang, L. An, Q. Tian, J. Lin, and S. Yang, "Gadoliniumlabelled iron/iron oxide core/shell nanoparticles as $T_{1}-T_{2}$ contrast agent for magnetic resonance imaging," RSC Advances, vol. 8, no. 47, pp. 26764-26770, 2018.

[46] L. Xu, S. H. Hong, Y. Sun et al., "Dual $T_{1}$ and $T_{2}$ weighted magnetic resonance imaging based on $\mathrm{Gd}^{3+}$ loaded bioinspired melanin dots," Nanomedicine: Nanotechnology, Biology and Medicine, vol. 14, no. 6, pp. 1743-1752, 2018.

[47] J. Yin, D. Chen, Y. Zhang, C. Li, L. Liu, and Y. Shao, "MRI relaxivity enhancement of gadolinium oxide nanoshells with a controllable shell thickness," Physical Chemistry Chemical Physics, vol. 20, no. 15, pp. 10038-10047, 2018.

[48] J. Liu, X. Tian, N. Luo et al., "Sub-10 nm monoclinic $\mathrm{Gd}_{2} \mathrm{O}_{3}$ : $\mathrm{Eu}^{3+}$ nanoparticles as dual-modal nanoprobes for magnetic resonance and fluorescence imaging," Langmuir, vol. 30, no. 43, pp. 13005-13013, 2014.

[49] Y. Yang, L. Lin, L. Jing, X. Yue, and Z. Dai, "CuInS $2 / Z n S$ quantum dots conjugating $\mathrm{Gd}(\mathrm{III})$ chelates for near-infrared fluorescence and magnetic resonance bimodal imaging," ACS Applied Materials \& Interfaces, vol. 9, no. 28, pp. 2345023457, 2017.

[50] Y. Liu, X. Zhi, W. Hou et al., "Gd ${ }^{3+}$-Ion-induced carbon-dots self-assembly aggregates loaded with a photosensitizer for enhanced fluorescence/MRI dual imaging and antitumor therapy," Nanoscale, vol. 10, no. 40, pp. 19052-19063, 2018.

[51] S. Mastrogiacomo, A. E. Kownacka, W. Dou et al., "Bisphosphonate functionalized gadolinium oxide nanoparticles allow long-term MRI/CT multimodal imaging of calcium phosphate bone cement," Advanced Healthcare Materials, vol. 7, no. 19, article e1800202, 2018.

[52] T. Tirusew, X. Wenlong, A. Md Wasi et al., Nanotechnology, vol. 26, p. 365102, 2015.

[53] J. Li, C. Wu, P. Hou, M. Zhang, and K. Xu, "One-pot preparation of hydrophilic manganese oxide nanoparticles as $T_{1}$ nano-contrast agent for molecular magnetic resonance imaging of renal carcinoma in vitro and in vivo," Biosensors and Bioelectronics, vol. 102, pp. 1-8, 2018.

[54] Z. Zhao, C. Sun, J. Bao et al., "Surface manganese substitution in magnetite nanocrystals enhances $T_{1}$ contrast ability by increasing electron spin relaxation," Journal of Materials Chemistry B, vol. 6, no. 3, pp. 401-413, 2018.

[55] J. Lee, N. Kumari, S. M. Kim et al., "Anchoring ligand-effect on bright contrast-enhancing property of hollow $\mathrm{Mn}_{3} \mathrm{O}_{4}$ nanoparticle in $\mathrm{T}_{1}$-weighted magnetic resonance imaging," Chemistry of Materials, vol. 30, no. 12, pp. 4056-4064, 2018.

[56] D. Liu, C. He, C. Poon, and W. Lin, "Theranostic nanoscale coordination polymers for magnetic resonance imaging and bisphosphonate delivery," Journal of Materials Chemistry B, vol. 2, no. 46, pp. 8249-8255, 2014.

[57] X. Shi and L. Shen, "Integrin $\alpha_{\mathrm{v}} \beta_{3}$ receptor targeting PET/ MRI dual-modal imaging probe based on the ${ }^{64} \mathrm{Cu}$ labeled manganese ferrite nanoparticles," Journal of Inorganic Biochemistry, vol. 186, pp. 257-263, 2018.

[58] J. Zhu, H. Li, Z. Xiong et al., "Polyethyleneimine-coated manganese oxide nanoparticles for targeted tumor PET/MR imaging," ACS Applied Materials \& Interfaces, vol. 10, no. 41, pp. 34954-34964, 2018.

[59] B. Li, Z. Gu, N. Kurniawan, W. Chen, and Z. P. Xu, "Manganese-based layered double hydroxide nanoparticles as a $\mathrm{T}_{1}$-MRI contrast agent with ultrasensitive $\mathrm{pH}$ response and 
high relaxivity," Advanced Materials, vol. 29, no. 29, article 1700373, 2017.

[60] B. Duan, D. Wang, H. Wu et al., "Core-shell structurized $\mathrm{Fe}_{3} \mathrm{O}_{4} @ \mathrm{C} @ \mathrm{MnO}_{2}$ nanoparticles as $\mathrm{pH}$ responsive $\mathrm{T}_{1}-\mathrm{T}_{2}$ * dual-modal contrast agents for tumor diagnosis," ACS Biomaterials Science \& Engineering, vol. 4, no. 8, pp. 3047-3054, 2018.

[61] Y. Liu, X. Lv, H. Liu et al., "Porous gold nanocluster-decorated manganese monoxide nanocomposites for microenvironmentactivatable MR/photoacoustic/CT tumor imaging," Nanoscale, vol. 10, no. 8, pp. 3631-3638, 2018.

[62] H. Hu, Y. Zhang, S. Shukla, Y. Gu, X. Yu, and N. F. Steinmetz, "Dysprosium-modified tobacco mosaic virus nanoparticles for ultra-high-field magnetic resonance and near-infrared fluorescence imaging of prostate cancer," ACS Nano, vol. 11, no. 9, pp. 9249-9258, 2017.

[63] D. González-Mancebo, A. I. Becerro, T. C. Rojas, M. L. Garcia-Martin, J. M. de la Fuente, and M. Ocana, "HoF3 and DyF3 nanoparticles as contrast agents for high-field magnetic resonance imaging," Particle \& Particle Systems Characterization, vol. 34, no. 10, article 1700116, 2017.

[64] X. Shi, K. Liu, T. Wang, S. Zheng, W. Gu, and L. Ye, "Formation mechanism of dysprosium-doped manganese carbonate nanoparticles by thermal decomposition," RSC Advances, vol. 6, no. 101, pp. 99339-99345, 2016.

[65] G. K. Das, Y. Zhang, L. D’Silva et al., "Single-phase $\mathrm{Dy}_{2} \mathrm{O}_{3}$ : $\mathrm{Tb}^{3+}$ nanocrystals as dual-modal contrast agent for high field magnetic resonance and optical imaging," Chemistry of Materials, vol. 23, no. 9, pp. 2439-2446, 2011.

[66] X. Jin, F. Fang, J. Liu et al., "An ultrasmall and metabolizable PEGylated $\mathrm{NaGdF}_{4}$ : Dy nanoprobe for high-performance $T_{1} /$ $T_{2}$-weighted MR and CT multimodal imaging," Nanoscale, vol. 7, no. 38, pp. 15680-15688, 2015.

[67] J. Yin, C. Li, D. Chen et al., "Structure and dysprosium dopant engineering of gadolinium oxide nanoparticles for enhanced dual-modal magnetic resonance and fluorescence imaging," Physical Chemistry Chemical Physics, vol. 19, no. 7, pp. 5366-5376, 2017.

[68] D. Ni, J. Zhang, W. Bu et al., "PEGylated $\mathrm{NaHoF}_{4}$ nanoparticles as contrast agents for both X-ray computed tomography and ultra-high field magnetic resonance imaging," Biomaterials, vol. 76, pp. 218-225, 2016.

[69] T. S. Atabaev, Y. C. Shin, S. J. Song, D. W. Han, and N. H. Hong, "Toxicity and T2-weighted magnetic resonance imaging potentials of holmium oxide nanoparticles," Nanomaterials, vol. 7, no. 8, p. 219, 2017.

[70] Y. Cao, L. Xu, Y. Kuang, D. Xiong, and R. Pei, "Gadoliniumbased nanoscale MRI contrast agents for tumor imaging," Journal of Materials Chemistry B, vol. 5, no. 19, pp. 3431-3461, 2017.

[71] D. S. Karaman, M. P. Sarparanta, J. M. Rosenholm, and A. J. Airaksinen, "Multimodality imaging of silica and silicon materials in vivo," Advanced Materials, vol. 30, no. 24, article e1703651, 2018.

[72] W.-Y. Huang, G.-L. Davies, and J. J. Davis, "High signal contrast gating with biomodified Gd doped mesoporous nanoparticles," Chemical Communications, vol. 49, no. 1, pp. 60-62, 2013.

[73] L. Zhang, R. Liu, H. Peng, P. Li, Z. Xu, and A. K. Whittaker, "The evolution of gadolinium based contrast agents: from single-modality to multi-modality," Nanoscale, vol. 8, no. 20, pp. 10491-10510, 2016.

[74] H. Wei, O. T. Bruns, M. G. Kaul et al., "Exceedingly small iron oxide nanoparticles as positive MRI contrast agents,"
Proceedings of the National Academy of Sciences, vol. 114, no. 9, pp. 2325-2330, 2017.

[75] D. Pan, A. H. Schmieder, S. A. Wickline, and G. M. Lanza, "Manganese-based MRI contrast agents: past, present, and future," Tetrahedron, vol. 67, no. 44, pp. 8431-8444, 2011.

[76] G.-L. Davies, I. Kramberger, and J. J. Davis, "Environmentally responsive MRI contrast agents," Chemical Communications, vol. 49, no. 84, pp. 9704-9721, 2013.

[77] D. Ni, W. Bu, S. Zhang et al., "Single $\mathrm{Ho}^{3+}$-doped upconversion nanoparticles for high-performance $T_{2}$-weighted brain tumor diagnosis and MR/UCL/CT multimodal imaging," Advanced Functional Materials, vol. 24, no. 42, pp. 6613-6620, 2014.

[78] L. Wang, H. Lin, X. Chi et al., "A self-assembled biocompatible nanoplatform for multimodal $\mathrm{mr} /$ fluorescence imaging assisted photothermal therapy and prognosis analysis," Small, vol. 14, no. 35, article e1801612, 2018.

[79] N.-N. Zhang, R.-S Yu, M. Xu et al., "Visual targeted therapy of hepatic cancer using homing peptide modified calcium phosphate nanoparticles loading doxorubicin guided by $\mathrm{T}_{1}$ weighted MRI," Nanomedicine: Nanotechnology, Biology and Medicine, vol. 14, no. 7, pp. 2167-2178, 2018.

[80] Y. Luo, E. H. Kim, C. A. Flask, and H. A. Clark, "Nanosensors for the chemical imaging of acetylcholine using magnetic resonance imaging," ACS Nano, vol. 12, no. 6, pp. 5761-5773, 2018.

[81] J. Zhou, T. Li, C. Zhang, J. Xiao, D. Cui, and Y. Cheng, "Charge-switchable nanocapsules with multistage $\mathrm{pH}$ responsive behaviours for enhanced tumour-targeted chemo/photodynamic therapy guided by NIR/MR imaging," Nanoscale, vol. 10, no. 20, pp. 9707-9719, 2018.

[82] W. Yang, X. Wu, Y. Dou et al., "A human endogenous protein exerts multi-role biomimetic chemistry in synthesis of paramagnetic gold nanostructures for tumor bimodal imaging," Biomaterials, vol. 161, pp. 256-269, 2018.

[83] B. Wu, S.-T. Lu, H. Yu et al., "Gadolinium-chelate functionalized bismuth nanotheranostic agent for in vivo MRI/ CT/PAI imaging-guided photothermal cancer therapy," Biomaterials, vol. 159, pp. 37-47, 2018.

[84] Y. Kuang, Y. Cao, M. Liu et al., "Geometrical confinement of gadolinium oxide nanoparticles in poly(ethylene glycol)/ arginylglycylaspartic acid-modified mesoporous carbon nanospheres as an enhanced $T_{1}$ magnetic resonance imaging contrast agent," ACS Applied Materials \& Interfaces, vol. 10, no. 31, pp. 26099-26107, 2018.

[85] F. H. Wang, K. Bae, Z. W. Huang, and J. M. Xue, "Two-photon graphene quantum dot modified $\mathrm{Gd}_{2} \mathrm{O}_{3}$ nanocomposites as a dual-mode MRI contrast agent and cell labelling agent," Nanoscale, vol. 10, no. 12, pp. 5642-5649, 2018.

[86] S. Wang, Z. Zhou, G. Yu et al., "Gadolinium metallofullerenepolypyrrole nanoparticles for activatable dual-modal imaging-guided photothermal therapy," ACS Applied Materials \& Interfaces, vol. 10, no. 34, pp. 28382-28389, 2018.

[87] J. O. Martinez, R. Molinaro, K. A. Hartman et al., "Biomimetic nanoparticles with enhanced affinity towards activated endothelium as versatile tools for theranostic drug delivery," Theranostics, vol. 8, no. 4, pp. 1131-1145, 2018.

[88] F. Du, L. Zhang, L. Zhang et al., "Engineered gadoliniumdoped carbon dots for magnetic resonance imaging-guided radiotherapy of tumors," Biomaterials, vol. 121, pp. 109-120, 2017.

[89] J. J. Liu, Q. Chen, W. W. Zhu et al., "Nanoscale-coordinationpolymer-shelled manganese dioxide composite nanoparticles: a multistage Redox/pH/ $\mathrm{H}_{2} \mathrm{O}_{2}$-responsive cancer theranostic 
nanoplatform," Advanced Functional Materials, vol. 27, no. 10, article 1605926, 2017.

[90] Q. Sun, F. He, C. Sun et al., "Honeycomb-satellite structured $\mathrm{pH} / \mathrm{H}_{2} \mathrm{O}_{2}$-responsive degradable nanoplatform for efficient photodynamic therapy and multimodal imaging," ACS Applied Materials \& Interfaces, vol. 10, no. 40, pp. 33901-33912, 2018.

[91] R. Liang, L. Liu, H. He et al., "Oxygen-boosted immunogenic photodynamic therapy with gold nanocages@manganese dioxide to inhibit tumor growth and metastases," Biomaterials, vol. 177, pp. 149-160, 2018.

[92] Y. Cao, X. Meng, D. Wang et al., "Intelligent $\mathrm{MnO}_{2} / \mathrm{Cu}_{2-\mathrm{x}} \mathrm{S}$ for multimode imaging diagnostic and advanced single-laser irradiated photothermal/photodynamic therapy," ACS Applied Materials \& Interfaces, vol. 10, no. 21, pp. 17732-17741, 2018.

[93] G. Yang, R. Zhang, C. Liang et al., "Manganese dioxide coated $\mathrm{WS}_{2} @ \mathrm{Fe}_{3} \mathrm{O}_{4} / \mathrm{sSiO}_{2}$ nanocomposites for $\mathrm{pH}$-responsive $\mathrm{MR}$ imaging and oxygen-elevated synergetic therapy," Small, vol. 14, no. 2, 2018.

[94] G. Yang, L. Xu, Y. Chao et al., "Hollow $\mathrm{MnO}_{2}$ as a tumormicroenvironment-responsive biodegradable nano-platform for combination therapy favoring antitumor immune responses," Nature Communications, vol. 8, no. 1, p. 902, 2017.

[95] Y. Wang, Y. Liu, H. Wu, J. Zhang, Q. Tian, and S. Yang, "Functionalized holmium-doped hollow silica nanospheres for combined sonodynamic and hypoxia-activated therapy," Advanced Functional Materials, vol. 29, no. 3, article 1805764, 2019.

[96] X. Y. Li, Q. Zou, L. Chen, and W. Li, “A ternary doped single matrix material with dual functions of bone repair and multimodal tracking for applications in orthopedics and dentistry," Journal of Materials Chemistry B, vol. 6, pp. 6047-6056, 2018.

[97] X. Zhang, B. Blasiak, A. J. Marenco, S. Trudel, B. Tomanek, and F. C. J. M. van Veggel, "Design and regulation of $\mathrm{NaHoF}_{4}$ and $\mathrm{NaDyF}_{4}$ nanoparticles for high-field magnetic resonance imaging," Chemistry of Materials, vol. 28, no. 9, pp. 30603072, 2016. 


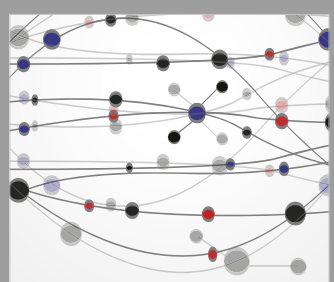

The Scientific World Journal
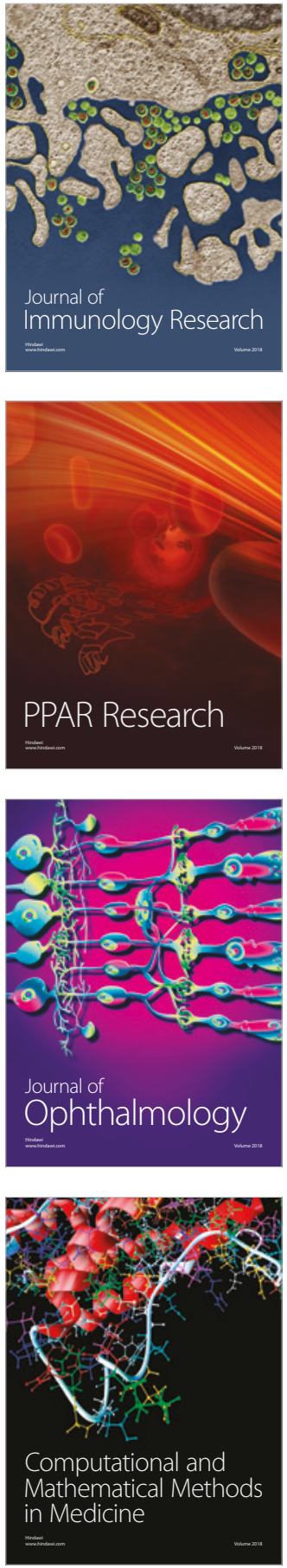

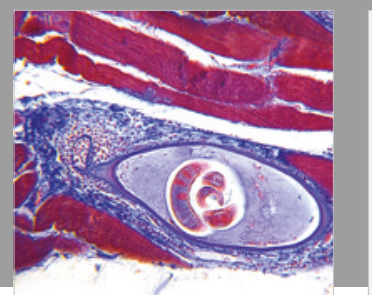

Gastroenterology Research and Practice

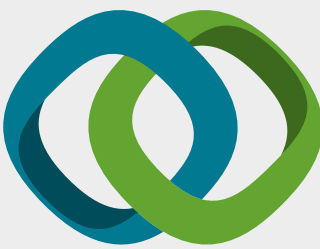

\section{Hindawi}

Submit your manuscripts at

www.hindawi.com
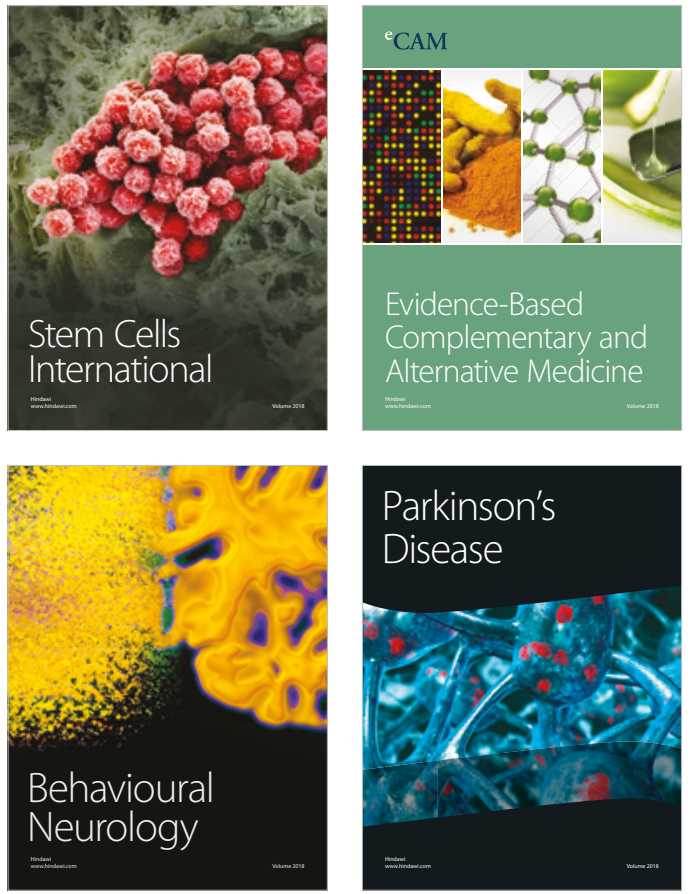

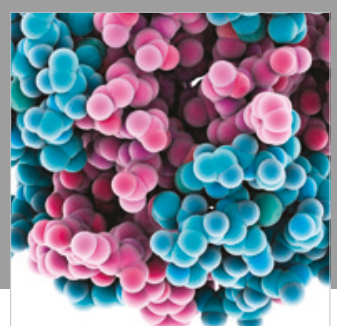

ournal of

Diabetes Research

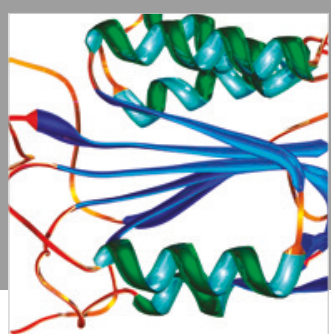

Disease Markers
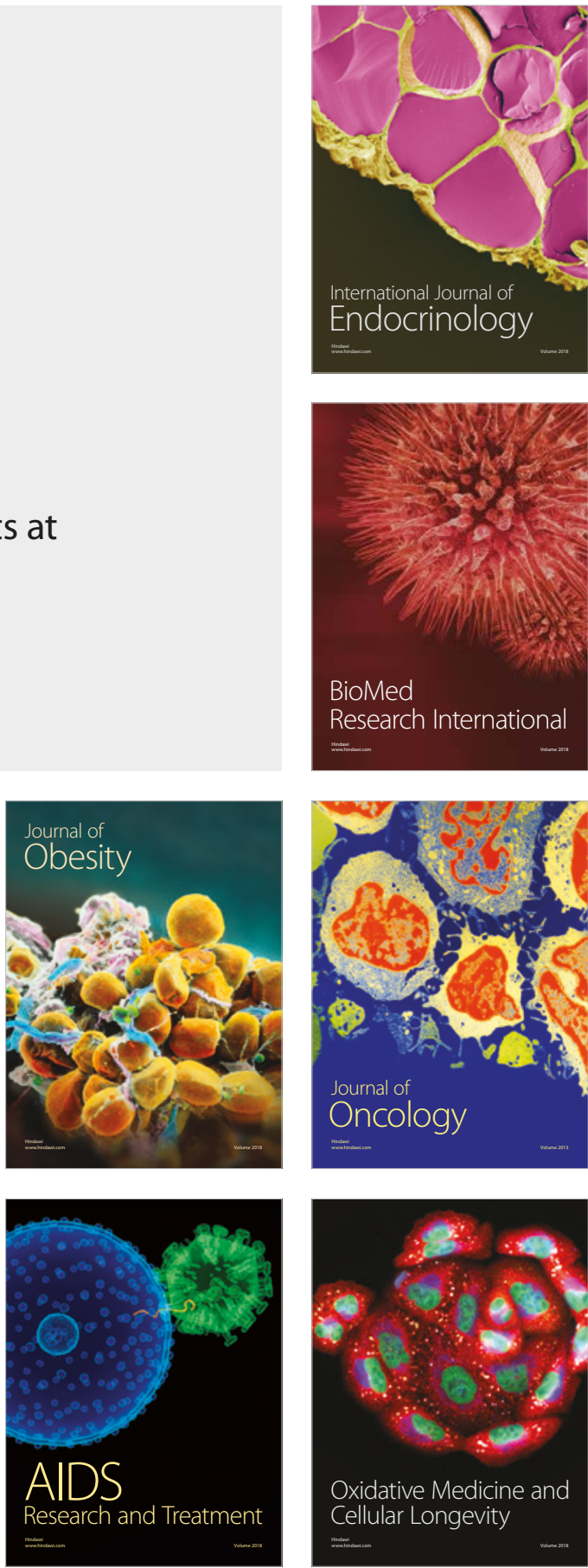